Illinois State University

ISU ReD: Research and eData

Theses and Dissertations

$4-26-2017$

\title{
The Redesign Of School Discipline: One School's Approach To Rethink And Redesign Discipline Practices Through The Restorative Justice Model
}

Heath J. McFaul

Illinois State University, mcfaulh@gmail.com

Follow this and additional works at: https://ir.library.illinoisstate.edu/etd

Part of the Curriculum and Instruction Commons, and the Educational Administration and Supervision Commons

\section{Recommended Citation}

McFaul, Heath J., "The Redesign Of School Discipline: One School's Approach To Rethink And Redesign Discipline Practices Through The Restorative Justice Model" (2017). Theses and Dissertations. 792. https://ir.library.illinoisstate.edu/etd/792

This Dissertation is brought to you for free and open access by ISU ReD: Research and eData. It has been accepted for inclusion in Theses and Dissertations by an authorized administrator of ISU ReD: Research and eData. For more information, please contact ISUReD@ilstu.edu. 


\title{
THE REDESIGN OF SCHOOL DISCIPLINE: ONE SCHOOL'S APPROACH \\ TO RETHINK AND REDESIGN DISCIPLINE PRACTICES \\ THROUGH THE RESTORATIVE JUSTICE MODEL
}

\author{
Heath J. McFaul
}

\section{Pages}

An overreliance on punitive discipline methods for addressing wrongdoing in schools has caused educational leaders to pause, and consider their alternatives. The enforcement of zerotolerance policies and the use of corresponding strategies like detentions, suspensions and expulsions, are no longer proving effective. These antiquated efforts focus only on the rules that were broken and the deserved punishment, failing to actually repair relationships and recognize root causes.

In 2014, U.S. Department of Education Secretary Arne Duncan stated, "The need to rethink and redesign school discipline practices is long overdue." Restorative discipline has emerged as an effective tool that responds to wrongdoing. This approach offers an alternative model that provides a respectful focus on accountability and the reparation of harm. The emphasis of restorative discipline is to recognize individual needs and to promote collaboration, cooperation, and problem solving.

This dissertation provides voice to the real-life work of student deans within a large high school setting as they redesign discipline practices to reflect a restorative model. Captured throughout the research are the personal anecdotes and experiences that have resulted in moments of success, hesitation and thoughtful consideration. Findings provide a detailed 
analysis of the implementation process, as well as a thorough examination of the largely problematic and antiquated use of zero-tolerance policies in education. Conclusions are also drawn to highlight the potential benefits the restorative justice model may have on school climate and how other schools can better prepare themselves for the challenges of implementation.

KEYWORDS: School Discipline; Restorative Discipline; Restorative Justice; Zero

Tolerance 
THE REDESIGN OF SCHOOL DISCIPLINE: ONE SCHOOL'S APPROACH

TO RETHINK AND REDESIGN DISCIPLINE PRACTICES

THROUGH THE RESTORATIVE JUSTICE MODEL

HEATH J. MCFAUL

A Dissertation Submitted in Partial

Fulfillment of the Requirements

for the Degree of

DOCTOR OF EDUCATION

School of Teaching and Learning

ILLINOIS STATE UNIVERSTIY

2017 
(C) 2017 Heath J. McFaul 
THE REDESIGN OF SCHOOL DISCIPLINE: ONE SCHOOL'S APPROACH

TO RETHINK AND REDESIGN DISCIPLINE PRACTICES

THROUGH THE RESTORATIVE JUSTICE MODEL

HEATH J. MCFAUL

COMMITTEE MEMBERS:

Brian R. Horn, Chair

Elizabeth Skinner

Gary Weilbacher 


\section{ACKNOWLEDGMENTS}

This work is dedicated to my family, an incredible wife Alyssa, and three amazing daughters Hadley, Hannah and Hilary.

Alyssa. You're my favorite teacher and best friend. Thank you for managing family life in my absence through years of coursework and writing. Your love and support has motivated me through several long days, and even longer weekends away from home.

Hadley, Hannah and Hilary. I am proud of many things in this life, but nothing beats being your father. I love your wondrous spirits, imagination and kindness to others. I want to be just like you when I grow-up. Now, let's go outside and play!

And to my parents, Jim McFaul and Colleen Goesling, thank you for building the foundation this dissertation is rooted in - a belief in second chances, the goodness of people, and the understanding that everyone has a story to share. With much love and appreciation to you both for shaping the person I am today.

I am also grateful to the school districts that have afforded me this opportunity, and to the many individuals that have encouraged my work in support of restorative discipline. Those directly involved in this research shall remain nameless, but their commitment of time, endless energy and sincere dedication are appreciated beyond measure. The students under their care and guidance are the ultimate beneficiaries of this research.

I would also like to extend my gratitude to Dr. Brian Horn, my committee chairperson. In addition to guiding me through some of the dissertation basics, Dr. Horn also served as a voice of reason whenever it was needed. I would also like to thank Dr. Elizabeth Skinner and Dr. Gary Weilbacher, for their time and commitment to this dissertation research committee. 


\section{CONTENTS}

Page

ACKNOWLEDGMENTS

CONTENTS

ii

CHAPTER I: INTRODUCTION

Problem Statement

Purpose of the Study

Significance of the Study

Closing

CHAPTER II: REVIEW OF THE LITERATURE

Historical Perspectives of Restorative Justice

Historical Origins of Restorative Justice

Developing the Definition of Restorative Justice

Historical Practices of Restorative Justice

Zero Tolerance: What It Is. What It Isn't

The Evolution of Zero Tolerance

The Application of Zero Tolerance

The Impact of Zero Tolerance

Moving Beyond Zero Tolerance

Authoritative, not Authoritarian

Restorative Justice in Schools

Implementation

Peace circles

Peer mediation

Implementation Results 
Research Design

Historical Perspectives and Use in Education 39

Participatory Action Research $\quad 40$

Research Questions $\quad 42$

Research Site $\quad 42$

Participant Recruitment and Selection $\quad 44$

The Research Participants 46

$\begin{array}{ll}\text { Meet the Participants } & 47\end{array}$

Heath $\quad 47$

Daley $\quad 49$

Richard $\quad 50$

Maggie $\quad 51$

Data Collection Methods $\quad 54$

Focus Group Interviews $\quad 55$

Individual Interviews $\quad 56$

Participant Perception Survey $\quad 56$

Analysis of Data $\quad 57$

Triangulation $\quad 59$

Ethical Considerations $\quad 59$

Research Limitations $\quad 60$

Definition of Terms 63

CHAPTER IV: RESEARCH RESULTS

Theme I: Appearance and Communication $\quad 67$

Theme II: Training and Support $\quad 75$

$\begin{array}{ll}\text { Theme III: Developing Relationships } & 81\end{array}$

CHAPTER V: RESEARCH SUMMARY AND CONCLUSION 87

$\begin{array}{lr}\text { Research Summary } & 88\end{array}$

Findings $\quad 93$

Implications and Recommendations for Practice 96

$\begin{array}{ll}\text { Closing } & 101\end{array}$

$\begin{array}{ll}\text { REFERENCES } & 103\end{array}$ 


\section{CHAPTER I: INTRODUCTION}

He sat across from me, hands clenched in rage and frustration, his chest heaving rapidly as tears began to form in the corners of his eyes. Moments ago, a heated verbal exchange in the hallway turned physical with a push and a tangled mess of punches being thrown. Although nearby staff separated the two students quickly, the bruised face (and ego) were already visible. From behind the comforts of my new and spacious desk, the process of interrogation began. This disciplinary conversation, like many before, and many after, would end with the same outcome, suspension. The length of time ranged anywhere from a single day, to a full week. And if the lost instructional time wasn't enough, some events involved an arrest for disorderly conduct, requiring multiple court dates and upwards of 30-40 hours of community service.

As a young administrator, my strict adherence to discipline policies and the following of past-practice was paramount to any personal feelings I may have had. In fact, I quickly learned to rationalize that by removing unruly students quickly and methodically, I was directly contributing to the greater-good of the learning environment. The robotics of this behavior never fazed me. Misbehave, get punished. This, in essence, would summarize my approach to 'disciplining' students. That is until I met Roland, ${ }^{1}$ a feisty freshman that would challenge everything I knew about school discipline practices.

Roland and I, quite literally, ran into one another in the fall of 2010 as a disgruntled looking staff member escorted him into the discipline office. In an effort of last-second bravado, he aggressively pushed through the office door, nearly knocking me over, as he spewed expletives and ranted about his unfair treatment in the hallway. It was Roland's freshman year,

\footnotetext{
${ }^{1}$ The names of all people and places in this study are pseudonyms.
} 
and my first year as a school administrator. In response, he received my canned behavioral reminder to follow adult directions at all times, and to show respect in the learning environment. I churned the discipline crank, and, with very little discussion, assigned Roland to Saturday School - a reasonable consequence given the overall situation. And so, it began. Roland would visit my office 21 times his freshman year. Referrals ranged from simple class truancy and insubordination, to verbal altercations and insubordination with staff. His consequences also ranged; from traditional detentions and Saturday school, to in-school, and out-of-school suspensions.

"Where did we ever get the crazy idea that to make people do better we first have to make them feel worse?" (Nelson, Lott \& Glenn 2000, p. 108). Admittedly, this is where I was in my relationship with Roland. With each new referral came more of the same conversations, and nothing ever changed. Phone calls home were never returned, and Roland's characteristic nonchalance grew ever more frustrating. This somewhat caustic pattern would continue time after time, until late spring, when Roland came into my office under his own accord - something was on his mind.

"Hey mister, we might be moving this summer, to Crawfordville, a different school district," he muttered. Where was that immediate sense of pleasure, that sense of total relief that I expected to feel when given news like this? One of the most difficult students on my entire caseload was leaving, I should be thrilled, right? Instead, in that moment, I saw that there was real pain in delivering this news to me. I also noticed that Roland was sharing this without his normal bravado and defensive mannerisms, he was being vulnerable. And, for the first time that school year, both Roland and I began to engage in a real conversation. A conversation where $I$ listened, and he spoke, not the other way around. For over an hour, I sat completely riveted to 
my chair as Roland shared story after story about his father's abandonment, homelessness, hunger, and how he and his mother escaped Mexico through a barbed-wire fence as helicopters tracked them through the night sky, across the border, and into Texas. Tears streamed down his face as he recalled his mother repeating "eres mi angelito...podemos hacer esto...eres mi angelito" (you are my angel...we can do this...you are my angel). Roland's gut wrenching accounts would eventually end with even more disheartening new of his current plight; sharing a rented bedroom in a small apartment where he sleeps on the floor next to his mother; amidst the chaos of a baby crying, neighbors fighting, and drugs being sold across the hall. It was something out of a Hollywood script, but there were no actors, and suddenly, there was a human being sitting there in front of me.

For the previous nine months, Roland Torres was just another ID number on my caseload, another pain-in-the-ass kid with behavioral referrals that served as an interruption to my already overloaded day. He took away precious time and energy from the other, more important, tasks of school leadership, but his conversation changed everything. Moving forward, Roland was a different kid, and I was a different administrator. For his part, Roland seemed to soften a bit. Although still truant and somewhat defiant to certain staff members, Roland was far less explosive. His behavior seemed to be more easily redirected, and even staff members that once feared his menacing demeanor came to see that something had changed. As the school year continued, Roland made more welcomed appearances to my office. Of course, there were times when Roland would just happen to arrive moments before a behavioral referral or frustrated teachers email, more and more he simply came by to share a story about his day, his newest efforts to find a job, or the girl he liked in math class. I took each of these impromptu visits as an 
opportunity to listen, sometimes with the offering of a little life-lesson, or sometimes just to simply learn more about what made him tick.

Before long it dawned on me, I was taking a new discipline approach with Roland, his referrals were decreasing and attitude towards school was improving. I was making a conscious decision to deal with his behavioral issues more constructively - looking to cooperate with him, instead of pushing back against him. What if other kids had a similar story...what if I started treating every student the same way I was treating Roland? What if?

\section{Problem Statement}

Although the meaning of the Latin root disciplina means "instruction given, teaching, learning, knowledge," my lived experiences with Roland existed on the premise that school culture was established through the enforcement of school rules and the corresponding punishment for violations (Morrison, Blood \& Thorsborne, 2005). The intent of a traditional school discipline program was simple; individuals that disrupt the learning environment are punished in order to change behavior and deter others from acting in a similar manner. When these consequences did not work to change said behavior, increasingly severe actions would be instituted until the student either learned to adapt properly, or was subsequently forced out of the educational system altogether. While this system may seem cruel, most traditional discipline policies were developed when schools were primarily geared towards the "best and brightest."

According to research from Sprick, Sprick, and Garrison (1992), the goal of our education system in the early 1900 s wasn't to educate all - as only $6 \%$ of the American population actually graduated from high school. The focus of education during the first few decades of the $20^{\text {th }}$ century was designed to advance a booming industrial revolution. The influence of economic and political leaders largely determined who would be educated, as 
gaining control of the educational system was a way to increase power over society (Spring, 2012). The financial devastation of the Great Depression reprioritized fiscal resources, and education lost out. Early in the decade, a panel of the National Economic League issued a list of "Paramount Problems in the United States"; in 1930 the condition of education was fourteenth among their concerns in 1930 it was twenty-fourth, and in 1932 thirty-second (Gale Database, 2001). Whereas business leaders were once the champions of education, helping to fund schools and training programs that were designed to promote a viable workforce, they were now seeking an immediate savings to their bottom-line. This immediate loss of funding had a catastrophic impact across the nation. In Chicago, the school board fired 1,400 teachers and reduced the salaries, and increased the teaching loads of the remainder. Schools throughout Iowa, Georgia and Alabama closed entirely, leaving thousands of students without access to formal education. By 1933 there were 200,000 unemployed teachers; 2.2 million children without school and 2,000 schools in 24 states failed to open (Gale Database, 2001).

Despite a nearly decade-long challenge, educational support regained momentum in the 1940s, thanks in large part to the development of standardized funding sources and a shortage of skilled workers from jobs left behind as a result of World War II. The increased demand for skilled labor widened the educational opportunities of those previously considered to be lacking in traditional qualifications based on race, gender or economic status. Trade schools now provided individuals with a skill set that allowed them to become productive members of society. High school graduation rates reached $50 \%$ of students by 1950 , and by the $1960 \mathrm{~s}, 75 \%$ of the population would earn their high school diploma. However, whether intentionally or unintentionally, schools continued to be exclusive through discipline policies that acted as tools 
to progressively weed out students with less ability or motivation than their more able peers (Sprick, Sprick \& Garrison, 1992).

The consequences of relying on suspensions and expulsions to remove students from school as a primary tactic to address misbehavior is nothing short of devastating (Biehl, 2011). Prior suspension is more likely to cause a student to drop out than any other factor, including low socioeconomic status, not living with both biological parents, or a high number of school changes (Spring, 2007). Students who are expelled from school entirely, that is removed from school for more than ten days, are even less likely to ever graduate - these costs are severe. Children who do not finish high school are 3.5 times more likely to be arrested as an adult. Additionally, approximately $82 \%$ of the adult prison population is composed of high school dropouts (Coalition of Juvenile Justice, 2010). There is also significant impact upon families, serving to further cement intergenerational poverty and the marginalized feeling that slowly erodes motivation and the hopes of working toward a better future. The cycle becomes one with a destructive outcome upon communities as well, with uneducated youth being more likely to commit crimes, or becoming the victim of a crime. Our overreliance on exclusionary discipline measures is to blame. And while the national graduation rate has grown to over $83 \%$, rates vary widely by state - from Florida, with the lowest average graduation rate at $65.8 \%$, to Nebraska, which has the highest graduation rate at 93.8\% (Boyington, 2017). The accuracy of these rates also has a wide range of skepticism, varying from state diploma requirements and the increased use of computer-based and self-paced programs, to educational placements that remove likely-tofail students from record by assigning them to alternative programs (Gewertz, 2017).

Moving away from these traditionally authoritative methods of school discipline has proven difficult as the rise of zero tolerance policies in the mid 1990's changed how school 
personnel would react to the wrongdoings of youth. The label of zero tolerance began with the Gun Free Schools Act of 1994, when Congress authorized public funding subject to school adoption of zero-tolerance policies (Cerrone, 1999). “Zero tolerance,” by its very nature and definition, is simple to implement and understand. Instead of principals and other school administrators dealing with misconduct on a case-by-case basis, considering the circumstances of the event, the specific students involved, and the repercussions for the overall safety of the school environment, many school districts now enforce zero-tolerance policies that greatly limit discretion in individual cases, involve law enforcement personnel, and mandate removing students from school (Kupchik, 2010).

While zero-tolerance gives the impression of strength as well as a higher standard of accountability for behavior, the negative effects of these punishments are well documented (Ashworth, Bockern, Ailts, Donnelly, Erickson, \& Woltermann, 2008; Kohn 1996; Losen \& Martinez, 2013; Skiba \& Peterson, 1999). Findings indicate that zero-tolerance policies fail to make schools safer through a swift and certain punishment. The common assurance that zerotolerance practices that immediately suspend a student who violates a school rule creates a more conducive learning environment has not been supported. In addition, while the notion of deterring future misbehavior is a central philosophy of zero-tolerance, evidence also suggests the opposite, that suspensions in general appear to predict higher future rates of misbehavior. Zerotolerance policies also fail to improve consistent discipline practices across racial subgroups and disabilities.

\section{Purpose of the Study}

There is a very real, and urgent need for change in the way schools continue to handle discipline. Consider this, when a young adult doesn't know how to read, we teach them how to 
read - but if a student misbehaves, we punish them. Just as we've done with instruction, the time has come to differentiate discipline. Roland, and students like him, deserve this individualized attention.

The purpose of this research study was to examine the work of school administrators as they review current practices, and examine the potential impact of a restorative discipline model in a large suburban high school. The school, Northwestern High School, opened its doors in 1949 and has followed a traditional discipline model for well over half a century. It is only within the past three years that school administration has begun to give serious thought and consideration to implementing restorative practices as an approach to student wrongdoing.

Action research will specifically target the work of student deans as they examine the effectiveness of their past-practices with that of the restorative model. The actions to be taken through this body of research are to make informed decisions based upon the success and drawbacks of implementation, specifically, about the effectiveness of restorative practices being applied to students, as well as the training, support and communication with staff. Ethnographic research data will be presented that captures the essence of what this team will work through; their struggles, apprehensions and those unique "ah-ha" moments. Data presented from this dissertation will represent the voices of those staff members directly involved in one restorative justice initiative.

\section{Significance of the Study}

My personal experiences with the implementation of a restorative justice philosophy were marred with struggle, requiring a major shift in thinking, and a realignment of commonly held beliefs about what discipline should actually look, and feel like. One of the most common misconceptions is that restorative discipline is a stand-alone program that comes with an 
instruction manual and is simply implemented into practice in order to deal with student behavior. Quite the opposite. Restorative discipline must be recognized as a philosophy, a new mindset that sees school discipline as an opportunity to educate, not punish. A successful restorative discipline approach needs to be part of the school culture, driving how all individuals treat one another. Most school discipline programs continue to exist based on retribution and punishment. Restorative philosophies look to create balance between offenders and those within the school environment that may have been negatively impacted by their actions, seeking to make things right - restoring relationships. This is a paradigm shift away from the traditional approach to student discipline that many schools are still practicing. I've made the mistake of acting robotically in response to a student's decision making, or not fully listening, or caring, to dive into the root causes. My early understanding of school discipline was based on the need to control the environment by controlling the students, thus, applying quick and heavy handed discipline in an effort to punish and discourage. Discovering the restorative discipline philosophy as an alternative to punitive discipline allowed me to grow professionally, more importantly, to help put at-risk students like Roland, back onto a better path.

This process took time, research, and the realization that that the values of restorative justice have been well adopted in many schools across the world in order to successfully build healthier learning environments for their students by addressing behavior in a manner that is more supportive and respectful (Amstutz \& Mullet, 2005). These schools are taking behavioral incidents that might otherwise result in punitive consequence, and creating rich learning opportunities. Students that participate in the restorative process, whether as victims or offenders, have an opportunity to learn important life lessons throughout the process, developing 
communication skills, building self-confidence, and equipping themselves to understand the importance of decision-making and accountability.

The findings of this study can serve as the spark for many schools considering implementation of restorative justice practices. This awareness is usually drawn from research data; examining various factors related to the success of staff and students in the educational setting. Qualitative data is also a source for developing awareness, as teachers, parents and the students themselves are likely to express their dissatisfaction with the adverse effects of current practices as they occur. Specific to this research study, the qualitative data will provide insight into the thoughtful work necessary to examine current practices and move forward with a restorative model.

\section{Closing}

I saw less and less of Roland as the school year drew to a close. Whenever we did find time to connect, he shared the disappointment of having to move, the frustration of starting all over again in a new school, and how he just wanted to drop-out. And before I knew it, the school year came to an end.

That summer, while attending a district meeting, a colleague of mine described an upcoming conference on the topic of 'Restorative Justice.' While I'd never heard that specific term before, I was intrigued by the conference description and made plans to attend. I was hooked. Days after the conference, using this newfound knowledge, I eagerly developed the framework for a school discipline model that was centered on the restorative philosophy. The details were well organized and included a matrix of restorative responses that could be applied at differing levels given a specific behavioral incident. I also included data suggesting how these practices will actually help improve daily attendance rates, and along with that, grades. There 
was a general rollout plan for staff, and a training calendar for those interested in learning more. Needless to say, I was eager to share this presentation with my colleagues upon our return that fall. The time, effort and energy I was putting forth into the development of a restorative program was going to be a true difference-maker!

"Oh boy, it looks like someone attended a conference this summer," was about all I needed to hear in order to understand exactly where this conversation was going. Like a punch to the gut, my presentation on restorative discipline practices was met with some general pleasantries from the more veteran co-workers, before moving on in the agenda to more important topics, like scheduling cafeteria supervision. There was a clear statement, the "newfangled" approach to discipline referrals sounded interesting, but would be something I pursued largely on my own accord.

This didn't bother me. I was sincerely energized with this new opportunity to 'shake-up' traditional discipline practices. And, just a few weeks later, while welcoming students back to another school year, I saw a familiar face in the crowd. 


\section{CHAPTER II: REVIEW OF THE LITERATURE}

The purpose of this research study is to examine the work of three disciplinary deans as they review current practices, and examine the potential impact of a restorative discipline model in a large suburban high school, determining whether such implementation serves as a worthwhile alternative to traditionally punitive approaches. This chapter will provide a historical perspective of the restorative justice philosophy, followed by literature related to current school discipline practices. Of primary importance is an analysis of the negative impact long-standing zero-tolerance policies has on young adults.

\section{Historical Perspectives of Restorative Justice}

There is a relative paucity in academic literature detailing the historical roots of the restorative justice movement throughout time. In most cases, the background of restorative justice is presented within a short, obligatory statement at the onset of an article, with the primary content focused more on the actual nature of the practice itself. While advocates often trace the restorative origin to various tribal cultures, places and times in history that reference indigenous practices and religious persuasions, there exists conflicting details.

\section{Historical Origins of Restorative Justice}

An analysis of justice practices from diverse cultures around the globe would indicate that many native or indigenous cultures utilized some form of restorative action in their attempts to maintain harmony within society. One of the most consistent references place the earliest view of restorative justice within the indigenous Maori culture of New Zealand, as well as to Native North American and First Nation Canadians. Restorative justice practices however, can be found in many ancient and indigenous cultures around the globe, including, African, Asian, Celtic, Hebrew, Arabic, and many others (Eagle, 2001; Goldstein, 2006; Mirsky, 2004; 
Roujanavond, 2005). Within many of these cultures, there exists a long-standing tradition of maintaining peaceful and harmonious relationships amongst their people.

Elmar Weitkamp's (1999) essay titled Restorative Juvenile Justice: Repairing the Harm of Youth Crime claims that "restorative justice has existed since human beings began forming communities" (p. 81), and later, "it's kind of ironic that we...go back to methods and forms of conflict resolution that were practiced some millennia ago by our ancestors who seemed to be much more successful than we are today" (p. 93). These sentiments were further echoed by Braithwaite (1989) in stating quite simply, "Restorative justice has been the dominant model of criminal justice throughout most of human history for the all world's peoples" (p. 2).

It seems reasonable then to suggest that restorative justice practices have long been present in human culture to varying degrees of implementation. While not designed to be a historical review of restorative justice, such milieu is used to frame the notion that restorative justice isn't something new.

\section{Developing the Definition of Restorative Justice}

While the actual term "restorative justice" was likely coined by Albert Eglash in 1958 when distinguishing between three approaches to justice, much of the paradigm shift towards restorative thinking in modern society can be attributed to Howard Zehr. Zehr (1990) authored the book Changing Lenses, which was first published in 1990, and considered to be groundbreaking in that it was also the first to articulate a theory of restorative justice (Johnstone, 2002). The title of the book itself is reference to the need for changing our view on how those in power treat criminal acts within society. When restorative practitioners first approached the criminal justice establishment, the ideas and practices they presented seemed a radical shift in what had been established as current practice in western societies (Johnstone, 2002). Zehr 
(1990) states "Ultimately, restorative justice provides an alternative framework for thinking about wrongdoing" (p. 3). Zehr (2002) would later publish another book focused specifically on Restorative Justice, aptly named The Little Book of Restorative Justice, which is intended to offer a focused perspective of the principles or philosophies of programmatic implementation. By the second half of the 1990's, the expression "restorative justice" had become popular, evolving to a universally agreed upon term and use by 2006 (Johnstone \& Van Ness, 2007). A working definition of restorative justice developed from the works of Howard Zehr (2002) states:

Restorative justice is a process which involves, to the extent possible, those who have a stake in a specific offense and to collectively identify and address harms, needs, and obligations in order to heal and put things back to as right as possible. (p. 37) As the values of restorative justice progressed, becoming more widely known and accepted, other organizations would also begin to develop their own definitions for use.

One of the most recognizable of these organizations is the United Nations, an international organization founded in 1945 that is committed to maintaining international peace and security by developing relations among countries and promoting better living standards and human rights. The United Nations definition was developed by Tony Marshall in 1996:

Restorative justice is a process whereby all parties with a stake in the particular offense come together to collectively resolve how to deal with the aftermath of the offense and its implications for the future.

By July 2002, the United Nations Economic and Social Council adopted "Basic Principles on the Use of Restorative Programmes in Criminal Matters" as a guide to encourage member nations to implement restorative justice in the operation of their domestic juvenile crime justice systems (McCold \& Wachtel, 2003). 


\section{Historical Practices of Restorative Justice}

In 1974, probation officer Mark Yantzi arranged for two teenagers to meet directly with their victims following a vandalism spree. They agreed to pay a restitution following the conference. The positive response from the victims led to the first victim-offender reconciliation program, in Kitchner, Ontario, Canada, with the support of the Mennonite Central Committee and collaboration with the local probation department (McCold \& Wachtel, 2003). Shortly thereafter restorative justice practices began sprouting up almost simultaneously around the United States and Canada as a response to a criminal justice system that was seen as ineffectual (Pranis, 2003). The existing juvenile justice philosophy was focused on punishment, not rehabilitation or early intervention. The need for development and true focus on youth reintroduction to society provided fertile soil for the growth or restorative justice (McGarrell, 2001).

Restorative justice has become a framework for thinking about ways of actually humanizing justice, or brining victims and offenders together in ways that provide opportunity for the victims to receive explanation and reparation, and for offenders to be accountable for their actions. Restorative justice has thus attracted many sympathizers across the political landscape, and seems to be rapidly gaining in popularity with community organizations,

politicians, and religious leaders, and, specifically for purposes of this research, our educational systems.

\section{Zero Tolerance: What It Is. What It Isn't}

In 1994, at the height of juvenile crime across the United States, President Clinton formally introduced zero tolerance to the national school system by signing the Gun-Free Schools Act, mandating an immediate expulsion of one calendar year for the possession of a 
weapon, as well as referral to the criminal or juvenile justice system (Gun Free Schools Act of 1994). This law marked the first time that government legislation began to intervene in school district administration and their traditional control over disciplining students (Pipho, 1999).

\section{The Evolution of Zero Tolerance}

Nationally, zero tolerance policies were already being applied to issues as diverse as environmental pollution, trespassing, skateboarding, racial intolerance, homelessness, sexual harassment, and boom boxes (Skiba \& Peterson, 1999). Yet just as these recognizably harsh policies were being phased out from the larger community due to weakened support and consistent application, the concept was gaining traction in public schools, fueled largely by the rise in juvenile arrest for violent crimes and a climate in which young people were increasingly seen as dangerous (Puzzanchera \& Adam, 2011). By the 1996-1997 school year, 79\% of schools had adopted some form of zero tolerance policies for violence (DeVoe, Peter, Kaufman, Miller, Noonan, Snyder, \& Baum, 2004).

The idea that rebellious or misunderstood young people were to be feared was magnified in 1999 at Columbine High School, spurring efforts to increasingly protect schools from dangerous youth (Kang-Brown, Trone, Fratello, \& Daftny-Kapur, 2013). This is the climate in which zero tolerance policies proliferated and also expanded to encompass a wide range of misconduct deemed less harmful than bringing a weapon to school (APA Zero Tolerance Task Force, 2008; Skiba, 2000; Skiba \& Peterson, 1999). Take for example the Massachusetts middle schooler that was immediately suspended from school after an assistant principal spotted a butter knife in her lunchbox that was packed by her mother to aide in cutting a pear. Or, that of an eight-year-old homeless student that lived with his mother in a car and accidentally grabbed a backpack with kitchen utensils, instead of his own similar looking backpack. When he opened 
the backpack of utensils in his classroom, which contained a knife, the school's zero-tolerance policy called for an automatic expulsion.

The federal government soon began to also increase funding for other, more visible safety measures, namely the presence of security personnel and law enforcement officials. Wherein the late 1970s there were reportedly fewer than 100 identified police officers in US public schools' (Brady, Balmer \& Phenix, 2007), there were 14,337 full-time school resource officers in 2003 (Hickman \& Reaves, 2006). In 2007, 68.8\% of American schools had "security personnel and/or assigned police officers" (Dinkes, 2009).

The rapid importation of police personnel and expertise into America's schools, along with policies and technologies that help manage school behaviors (surveillance cameras, metal detectors, law enforcement referrals), undoubtedly has changed the character of school discipline (Hirschfield \& Celinska, 2011). School misbehavior that formerly prompted detention or suspension now routinely or automatically triggers arrest and referral to court (Rimer, 2004). Many scholars contend that contemporary patterns of school security and punishment manifest or advance 'criminalization', whether of student behavior (Theriot, 2009), school discipline (Hirschfield, 2008), 'poor students' (Kupchik \& Monahan, 2006), school governance (Simon, 2006), 'youth difference' (Lyons \& Drew, 2006), and a host of other social issues. It's of no surprise that incarceration rates for juveniles have thus increased more than threefold since 1980 (Hirschfield \& Celinska, 2011).

\section{The Application of Zero Tolerance}

Advocates for zero tolerance policies claim that it prevents school violence by removing dangerous students immediately after an infraction and, simultaneously, sends a strong deterrent message to other students (Gregory \& Cornell, 2009). In addition, zero tolerance policies lay 
claim to discipline approaches that are said to be applied fairly to everyone as they mandate the application of predetermined consequences regardless of the gravity of behavior, mitigating circumstances, or situational context. Similar to punitive responses in the justice system, such as sentencing guidelines and mandatory minimum sentencing, zero tolerance disciplinary codes in schools attempt to structure theoretically rational and equitable consequences for serious misbehavior (such as drugs and weapons in school) proportionate to the harm caused (Bazemore \& Schiff, 2010; Schiff, 2013) Zero tolerance, by general definition, is a highly structured disciplinary policy that permits little flexibility in outcome by imposing severe sanctions (often long-term suspension or expulsion) for even minor violations of a school rule.

A hallmark of zero tolerance is that it permits little or no consideration of the student's intentions or the circumstances of his or her misbehavior (Heaviside, Rowand, Williams, \& Farris, 1998; Skiba \& Peterson, 1999). Under such practice, issues of noncompliance and misbehavior in school exclusively focus discipline attention on punishments that often exclude students from the educational setting; suspensions or expulsions. The numbers of secondary school students suspended or expelled over the course of one school year increased 40 percent from one in 13 in 1972-73, to one in nine in 2009-10. In recent years, an estimated two million students annually are suspended from secondary schools (Losen \& Martinez, 2013). As a point of comparison, slightly more than three million students graduated from high school across the nation in 2013 (NCES, 2013).

Many school districts continue to use zero-tolerance policies despite little research to support their effectiveness. Instead, relying on the public perception that these policies make students feel safer and result in an improvement in behavior (Skiba, 2000; Skiba \& Peterson, 2000). Skiba (2000) and Skiba and Peterson (2000) report that through a database search they 
located only six empirical studies that evaluated security measures, none of which addressed the use of zero tolerance policies; instead, these studies examined other school discipline deterrents such as locker searches, video surveillance cameras, and school uniforms.

\section{The Impact of Zero Tolerance}

While there is little argument that school personnel have a responsibility to create and maintain a safe and disciplined educational environment, and that without such, schools would be marred with unruly behavior disruptive to teaching and learning, the effectiveness of zero tolerance has not been validated. To the contrary, much of the available research would suggest that school exclusion practices have a negative effect on students and lack any sort of preventative function (APA Zero Tolerance Task Force, 2008; Skiba \& Peterson, 1999). In fact, the very enactment of zero tolerance policies related to discipline has actually contributed to significant increases in the number of students actually being expelled, suspended, or otherwise removed from school (Noguera, 2003).

The impact of the zero tolerance policies is a marked lack of dignity for the offending youth who is summarily dismissed from either the classroom or the school. This often occurs with little or no say from the offender as to what happened nor what the appropriate consequence should be, nor effective strategies for reengagement once having been excluded from the school structure (Schiff, 2013). To compound this ever further, the students receiving such punishment are most often those in need of the greatest academic, social, economic and emotional supports often provided by the educational setting. Further, the students expelled or removed from the classroom setting for punishment are frequently low-achieving minority males (especially African-American and Latino). 


\section{Minority Overrepresentation in School Discipline}

Despite what appears to be a relatively neutral policy as far as how it treats offenders, "zero tolerance" practices have actually been linked to increased disparities and discrimination. Nationally, black and Latino students are suspended and expelled at a much higher rate than white students, and boys are twice as likely as girls to receive these punishments (Losen \& Martinez, 2013). One study in particular found that Black students are punished more severely for lesser offenses, such as "disrespect, excessive noise, threat or loitering" than their White peers (Skiba, Michael, Nardo, \& Peterson, 2002). Black students represent $16 \%$ of the student population, but $32-42 \%$ of students suspended or expelled. In comparison, white students also represent a similar range of between $31-40 \%$ of students suspended or expelled, but they are $51 \%$ of the student population. Black students are suspended and expelled at a rate three times greater than white students. On average, $5 \%$ of white students are suspended, compared to $16 \%$ of black students. (United States Department of Education Office for Civil Rights, 2014a).

While fighting is the most frequently stated reason for suspensions, the majority of school suspensions occur in response to relatively minor incidents such as failure to follow directions or inappropriate language, that do not threaten school safety (Skiba \& Rausch, 2006). One hypothesis for the racial bias in suspension data related to minority overrepresentation in school discipline considers socioeconomic factors, suggesting that inequitable racial treatment in discipline may be related to issues of poverty, not race (Noltemeyer \& McIoughlin, 2010).

Research also suggests that the process of disproportionality is likely to begin in the classroom with the teacher referral (Gregory \& Weinstein, 2008). Casella, (in Fenning \& Rose, 2007) finds that minority groups in particular are not "fitting in" to the school norm, and that by not "fitting in" they are subsequently labeled as "dangerous." Once labeled in this manner, these 
identified groups of students (who are primarily poor ethnic minority students and those with academic problems) are more often removed primarily for nonviolent infractions found in school discipline policies (Skiba \& Peterson, 2000). Fenning and Rose (2007) assert that the fear of losing control in the classroom on the part of educator sheds light on why our most vulnerable students often fall into a web of exclusionary discipline consequences. Students of color are unfortunately targeted as part of this fear and anxiety, thus becoming more likely to be on the receiving end of strict and often rigid punitive discipline consequences (Fenning \& Rose, 2007). Those who are not perceived to fit into the norm of school (because of race, poor academic performance, socioeconomic status [SES]) are also unjustly targeted for removal.

The American Psychological Association (APA), as part of its mission to advance health, education and human welfare, commissioned the Zero Tolerance task force to examine evidence related to the effectiveness of zero tolerance policies. Of particular interest to this review is data regarding the effects of exclusionary discipline on students of color, and their relationship with education and the juvenile justice system. The following is a summarized version of the key findings presented by the APA Zero Tolerance Task Force (2008) that pertain more specifically to this research study.

1. Have zero tolerance policies made schools safer and more effective in handling discipline issues?

Although any level of violence and disruption in school is unacceptable, data does not suggest the assumption that violent acts are increasing. Violence in school remains a relatively small portion of disruption, and has either remained stable or decreased through time (DeVoe et al., 2004; Heaviside et al., 1998). In cases in which zero tolerance policies have been enforced, and the disruptive student has been removed from the 
school, data does not suggest that a safer climate has been established. In fact, research has shown the opposite effect; that schools with higher rates of suspension and expulsion appear to have less satisfactory ratings of school climate and spend a greater amount of time dealing with continued discipline matters (Skiba \& Rausch, 2006). Research from Bowditch (1993), Costenbader and Markson (1998), Raffaele-Mendez and Knoff (2003), and Tubin, Mioduser, Nachmias, and Forkosh-Barauch (2003) all suggest that long-term suspensions and expulsions appear to predict higher future rates of misbehavior and are moderately associated with a higher likelihood of school dropout.

2. What has been the impact of zero tolerance on students of color?

Advocates of zero tolerance believe that by removing subjective influences or contextual factors from disciplinary decisions, such policies would be fairer to students traditionally overrepresented in school discipline consequences (Casella, 2003). Research has, however proven this ideal to be unfounded time and time again for African-American and Latino students (Costenbader \& Markson, 1998; Kaeser, 1979; McCarthy \& Hoge, 1987; McFadden, Marsh, Price \& Hwang, 1992; Raffaele-Mendez \& Knoff, 2003; Skiba et al., 2002; Wu, Pink, Crain, \& Moles, 1982). Moreover, the research has overwhelmingly shown that disproportionality cannot be supported by other assumptions as well, such as economic disadvantage or exhibiting higher rates of disruption or violence. Rather, African American students may be disciplined more severely for less serious and more subjective reasons (Skiba et al., 2002).

Recent professional opinion, research and literature suggest that a lack of teacher preparation in classroom management and culturally competent practice may also factor 
into the disproportionate discipline data (Ferguson 2001; Townsend, 2000; Vavrus \& Cole, 2002).

3. How has zero tolerance affected the relationship between education and the juvenile justice system?

Media attention over the development of safer school climates grew as a direct result of more violent acts taking place within educational settings. As a result of this violence, schools came to also rely upon the use of school resource officers, security technology, student profiling and increased supervisory personnel. This is especially true in the urban high school settings of high minority student populations and high-poverty neighborhoods. Although these resources may be useful as part of a comprehensive approach to prevention, there is insufficient evidence to suggest that these resources are effective in promoting safer schools (Skiba \& Rausch, 2006).

The increased reliance upon more severe school consequences has resulted in increased referrals to the juvenile system (Wald \& Losen, 2003). This school-to-prison-pipeline has emerged in literature (Advancement Project, 2005; Heitzeg, 2009; Nelson \& Lind, 2015; PEW Center on the States, 2008), and indicates that schools appear to be using this system as a means to deal with problems previously not associated with the juvenile system, rather than handled within the school. It is reference to the correlations made between the juvenile court system and school discipline. More specifically, that minority youth are disproportionately impacted by these strictly enforced discipline policies.

Although zero tolerance policies project to the community a strong message that violence of any kind, as well as aggressive and other unwanted behavior is not tolerated, the policy itself seems to be inherently unfair as the punishments associated with zero tolerance tend to put 
students at greater risk for decreased engagement in school, increased participation in risky or illegal behavior, poor academic achievement and dropout, and, for many, subsequent entry into the school to prison pipeline (Boccanfuso \& Kuhlfield, 2011; Casella, 2003).

Research makes clear that the schools implementing zero tolerance policies have yet to present any sufficient form of evidence to support the ongoing use of such a model. Discipline in schools has the potential to be used as a positive force behind students learning to take responsibility for their actions, yet zero tolerance policies continue to fall short of expectations, and continue to cause real harm to the individuals impacted by such practice.

\section{Moving Beyond Zero Tolerance}

Zero-tolerance was originally intended as strict policy that would improve school safety by removing students, regardless of race, ability, or parental influence, if they failed to follow the rules. In an effort to treat all students the same, there is a need for more individualized, corrective measures (Curwin \& Mendler, 1999). In their book, As Tough as Necessary: Countering Aggression, Violence and Hostility in School, authors Richard Curwin and Allen Mendler (1999) state that such a "one size fits all” approach to unwanted behaviors is flawed, and that student individuality must be taken into account on all major infractions.

Additional studies have also shown that restorative practices can reduce a juvenile's further contact with law enforcement and the court system (Bouffard \& Berseth, 2008; Latimer, Dowden \& Muise, 2005; Luke \& Lind, 2002; McGarrell, 2001). This amassed evidence makes a clear case for moving away from zero tolerance practices in educational settings as well.

\section{Authoritative, not Authoritarian}

Anne Gregory and Dewey Cornell (2009) approach zero tolerance by analyzing research literature of effective parenting. Zero tolerance is an approach to discipline that is highly 
structured and rigidly punitive. In parenting literature, Diana Baumrind (cited in Gregory \& Cornell, 2009) labels this approach as authoritarian because it emphasizes a high degree of structure and control with an absence of understanding. Baumrind describes authoritarian parents as "demanding and directive, but not responsive. They are obedience and status-oriented and expect their orders to be obeyed without explanation" (p. 107). In a school setting, this applies similarly to a zero-tolerance approach, which allows for little latitude, expecting strict obedience and adherence to all rules set forth, regardless of any circumstantial explanation. Such an approach is broad sweeping and does not allow for any type of individualized argument, and would often be associated with negative outcomes. Baumrind indicates that adolescents with authoritarian parents show low social competence and high psychological distress.

Baumrind (cited in Gregory \& Cornell, 2009) asserts that a parent with authoritative control balances the adolescent need for the enforcement of rules and monitoring, with the responsiveness to their individuality. Baumrind states that "authoritative control can achieve responsible conformity with group standards without loss of individual autonomy or selfassertiveness" (p. 107). Later, she comments that authoritative parents "monitor and impart clear standards for their children's conduct. They are assertive, but not intrusive or restrictive. Their disciplinary methods are supportive rather than punitive" (p. 107). Although Baumrind never uses the word "restorative" in her writing, it is found to be equivalent to being authoritative, representing the exercise of authority in a supportive manner. She found that parents who were authoritative were more effective as parents and got better results than the authoritarian parents who were punitive (Wachtel, 2009).

The use of a parenting model as framework for the development of what school disciplinary practices should look like can be a difficult stretch. Yet we continue to struggle as 
an educational system under the same guidelines we've been adhering to for decades. It is refreshing to learn of some school districts that are taking strides towards an alternative path. Take for example a study of 296 public high schools in Virginia, in which Gregory and Cornell (2009) collected survey data from randomly selected samples of approximately 7,400 ninth grade students and 2,900 teachers. Their research identified indicators of school wide structure and support, and examined how student experiences with authoritarian or authoritative factors influences their attitudes toward learning and academic performance (Gregory \& Cornell, 2009). Results indicated that students want administrators to keep their school safe and orderly, yet at the same time communicated the importance of being listened to and treated with respect (Gregory \& Cornell, 2009).

Under a model of authoritative discipline, school officials would be allowed to make judgments about the seriousness of an infraction and to consider the adolescent's intent and circumstances of the behavior. The young adult(s) involved would be treated with greater respect when listened to, and allowed to share their personal narrative of any potential antecedents that may have led to the events. More importantly, the individual punishment or consequence will be aligned to better represent the overall scope of the misbehavior, as well as create a feeling of support and a sense of justice and fairness for the adolescent.

The link between authoritative parenting and restorative discipline exists because both employ control and support. Wrongdoing is confronted and disapproved of, while also being supportive and showing value to an individual's self-worth and dignity. Both authoritative parenting and restorative discipline take into account an individual's unique needs and set of circumstances in their response, and seek to repair harm. Authoritative parenting and restorative 
discipline practices exist in contrast to the authoritarian approach and zero-tolerance practices that are seen as controlling, punitive, and lacking in support.

It is of no surprise then, that the philosophical principles of a restorative justice model have been implemented in many schools across the nation as an alternative to the traditional disciplinary process (Ahmed, Harris, Braithwaite, \& Braithwaite, 2001; Calhoun, 2000; Karp \& Breslin, 2001; Morrison, 2001; Morrison et al., 2005; Wachtel, 1999).

\section{Restorative Justice in Schools}

While much of our national attention focuses on test scores and achievement data, there is a growing trend that also recognizes the important balance between a students' sense of safety and security, as well as the disciplinary practices to which they must abide (United States Department of Education, 2014b). In response, restorative justice has been applied in many schools across the world in order to successfully build healthy communities, support students and teachers, and to help address discipline issues. These schools are taking behavioral incidents that might otherwise result in punitive consequence, and create rich learning opportunities for young adults.

The use of punitive disciplinary actions and zero tolerance policies has been relied upon to maintain a safe learning environment for students. Despite the use of punitive, exclusionary disciplinary practice, research suggests that effective strategies for creating a safe school should use discipline as a tool to teach acceptable behavior (Hamilton, 2008; Skiba \& Peterson, 2003), include an array of options for addressing challenging student behavior (APA, 2008), establish procedures to ensure that disciplinary processes are fair and consistent, and involve restorative justice strategies that focus on restoring the harm caused by a wrongdoing (Amstutz \& Mullet, 2005; Morrison et al., 2005). 


\section{Implementation}

The implementation of a restorative justice philosophy requires a major shift in thinking and realignment of the commonly held beliefs about what discipline should actually look, and feel like, in the educational setting. Varied degrees of implementation exist, ranging from single programs used by specific groups or individuals, to formal programs being instituted across entire districts.

In 1993, the U.S. Department of Justice Office of Juvenile Justice and Delinquency Prevention (OJJDP) established the Balanced and Restorative Justice (BARJ) program by providing grant funds to Florida Atlantic University (FAU). In 1994, the BARJ project, with cooperation from the Center for Restorative Justice and Mediation through a subcontract with the University of Minnesota, began to provide training and technical assistance to develop policy and practice pertinent to the restorative model. While the BARJ project was initially focused on matters of criminal justice, the model was adapted as a justice tool to also guide a wide range of conflicts, not just those that broke a particular law, ordinance or municipal code. In 2003, the Illinois BARJ Initiative (IBARJI) was founded in order to raise and use funds to further advance the program efforts within the state. This included the establishment of regional restorative justice training offices in 2005, and coordinated efforts with local school districts to provide statewide support in 2007.

These training programs, along with the release of Implementing Restorative Justice: A Guide for Schools (Ashely \& Burke, 2009), provided schools with much-needed support. While these formal guidelines and trained individuals are a necessary component to help with successful implementation, it remains important to note that Restorative Justice is not, in and of itself, a program. Restorative Justice is a philosophical approach that views wrongdoing as an 
opportunity to provide support and effective communication between those affected in an attempt to encourage accountability and the reparation of harm. It can sometimes be presumed that because 'training' is taking place, there must be a programmatic attachment as well. Training, in this sense, is educational in nature in that individuals learn how to see discipline through a new lens, and that various practices contribute to the success of this approach.

As outlined in the Implementing Restorative Justice: A Guide for Schools (Ashley \& Burke, 2009), the most common restorative practices adopted by schools are (1) Peace Circles, (2) Peer Jury, and (3) Peer Mediation.

Peace circles. The practice of peace-circles, also referred to simply as circles, in restorative justice is one of the most widely practiced elements of implementation (Zehr, 2002). This practice includes victims, offenders and trained facilitators being brought together in a proactive nature in order for each member of the circle to have a voice in the overall communication process. As Ashley and Burke (2009) state, "by offering opportunities for safe and open communication, circles help resolve conflict, strengthen relationships between participants, emphasize respect and understanding, and empower all parties involved" (p. 14). Throughout, all types of students, from those highly engaged, to those requiring the most support, are encouraged to participate by listening respectfully, responding appropriately, and accepting responsibility. Students, the facilitators and other key stakeholders (parents, school personnel, community members, etc.) are invited to "circle-up" in order to open meaningful communication designed to address a recent wrongdoing or community concern.

In support of peace-circles, data from the South St. Paul School District of Minnesota, found that students in several schools experienced fewer suspensions, fewer expulsions, fewer behavioral referrals, and greater overall attendance (Stinchcomb, Bazemore \& Reistenberg, 
2006). Additionally, schools in Peoria, Illinois implemented circles and experienced a $35 \%$ drop in referrals to detention, and a $43 \%$ drop in detentions referrals for black students, who are often disproportionately assigned detention (Brown, Snyder, Hurst \& Berry, 2010).

Peer jury. Another common practice is the use of a peer jury process, sometimes referred to as a teen-court or peer-court. Once again, this practice centers on the development of youth accountability through a court process with youth (peers) acting as the jurors - offering guidance and support to the referred individual, and developing an agreement that outlines actions needed by the student in order to repair harm. Referred students are also given community resources to address root causes of their behavior and identify positive solutions (Ashley \& Burke, 2009). Interestingly, the jurors are not often your exemplary student, rather students that have been previously referred, allowing them to take leadership roles in every level of the process.

In 2001, Chicago Public Schools (CPS) piloted peer jury programs using restorative justice principles in several schools. Peer juries now represent one of the few non-punitive, alternative, disciplinary processes in CPS. By 2009, 45 Chicago high schools had implemented peer jury programs. In the 2007-2008 school year, $90 \%$ to peer jury agreements were completed. An evaluation found that from academic years 2005 to 2007, CPS peer juries helped students avoid more than 1,000 days of suspension (Olson \& Viola, 2007).

Peer mediation. Peer mediation is commonly used in an effort to settle conflicts between students through the use of trained peers. These programs generally teach students about healthy resolutions to conflict and how improved communication can often help resolve misunderstandings. Student mediators apply restorative problem solving techniques, such as listening and speaking, under the guidance and direction of trained adult mediator. Discussions are designed to not only hold students accountable for their actions, but to also provide time to 
schedule additional conversations or apply other layers of support. Peer mediation is also helpful in keeping less serious incidents from escalating to something more serious later in time. Ultimately, all students gain from the experience, and learn skills that can be applied to future conflicts they man encounter.

A study of eight Canadian high schools found that peer mediators can peacefully resolve conflicts, are trusted by students, and are exemplary student leaders. Furthermore, peer mediation teaches life skills, provides leadership and provides an alternative to suspension (Samuels, 2001).

\section{Implementation Results}

In 2009, the International Institute for Restorative Practices (IIRP) published Findings from Schools Implementing Restorative Practices. This report highlighted the practices being implemented from six schools in Pennsylvania ranging from urban to rural, and from moderately affluent to poverty stricken. Each school had implemented the Safer-Saner-Schools program, developed by the IIRP president, Ted Wachtel. Instead of zero tolerance and authoritative punishment, restorative practices in the school settings place responsibility on students themselves, using a collaborative response to wrongdoing (Mirsky, 2003). According to the research, such restorative practices hinge upon the strategy that involves changing relationships by engaging people in a manner that does things with them, rather than to them or for them (Mirsky, 2003).

The Wachtel pilot program has grown to include public schools in the surrounding area as well. Data revealed decreases in behavioral suspensions, referrals and recidivism rates. Other educational settings have found similar results: 
- At Cole Middle School in Oakland, CA suspensions declined by $87 \%$ and expulsions to zero during the implementation of whole-school restorative justice (Summer, Silverman \& Frampton, 2010).

- Using restorative circles, conference and peer mediation and other approaches, the restorative discipline programs outlined by the Minnesota Department of Education helped significantly reduce behavioral referrals and suspensions in two high schools by 45 to $63 \%$, increased academic achievement and significantly reduced behavioral referrals and suspensions. In a recent survey, 277 schools principals reported that their schools used restorative practices (Minnesota Department of Education, 2011).

- In Denver, Colorado, a combination of informal classroom meetings, victim impact panels and restorative conferencing resulted in a $68 \%$ overall reduction in police tickets and a $40 \%$ overall reduction in out-of-school suspensions at seventeen schools (Advancement Project, 2010).

- In San Antonio, TX, Ed White Middle School implemented restorative practices in 2012; they saw in-school-suspension for conduct violations drop by $65 \%$, and out of school suspensions dropped by 57\% (Armour, 2014).

Results such as this have given rise to other school systems looking to emulate such results. In 2008, for example, restorative practices were integrated into the Chicago Public Schools Student Code of Conduct and a school implementation guide was developed for the District (Ashley \& Burke, 2009). Some state legislation has also been introduced as well, naming restorative justice specifically as an alternative to zero tolerance in schools. Florida amended Section 3, 1006.13 to read "to encourage schools to use alternatives to expulsion of referral to law enforcement agencies by addressing disruptive behavior through restitution, civil 
citation, teen court, neighborhood restorative justice, or similar programs...” (Thompson, 2016). Similarly, legislative amendments to include restorative justice wording has taken place in Minnesota and Colorado. Policymakers have gone as far as introducing legislation to enable funding at the federal level (Schiff, 2013)

There is a plethora of evidence both nationally and internationally, supporting the various restorative philosophies being developed in school districts that have shown reductions in suspension and expulsion rates and discipline referral recidivism (Advancement Project, 2010; Armour, 2013; Bazemore \& Schiff, 2009; Burke 2013; Mirsky, 2011). In addition, reports show improved academic achievements and other beneficial results that improve the learning environment (Arnott, 2007; Karp \& Breslin, 2001; Lewis, 2009; Morrison, 2001; Riestenberg 2006). Studies have also shown that victims and offenders are generally satisfied with the results of restorative justice practices (Braithwaite, 2002; Latimer \& Kleinknecht, 2000; Latimer et al., 2005).

Kajs (2006) found that when consequences are applied fairly, school discipline policies and actions can have a beneficial effect on the development of character and can result in a safe environment conducive to student learning and growth. Students of color specifically, are even more profoundly impacted by discipline practices applied in a restorative manner. In 2012, a study conducted by the Regional Educational Laboratory of Education Northwest (REL) examined not only the disproportionate use of exclusionary practices upon students of color, but also a summary of practices associated with discipline referrals that reduced racial disproportionality. It is of little surprise that the strategies outlined by the REL research to improve discipline practices for youth of color run parallel to the framework of restorative discipline; showing interest in the welfare of students, being sensitive to social needs, setting 
high expectations, respecting the student perspective, and proving positive recognition (Regional Educational Laboratory of Education Northwest, 2012). In similar research, schools with lower racial disproportionality were found to have discipline environments that were considered proactive, seeking to prevent problems as opposed to strictly enforcing school rules (Brackett, Reyes, Rivers, Elberston, \& Salovey, 2012). Additionally, schools with low rates of suspension were more likely to use restorative discipline responses such as referrals to school counselors, conferences with students and parents, restitution and community service (Payne \& Welch, 2010). On the other hand, administrators of schools with high suspension rates were more likely to assign in-school or out-of-school suspension for misbehaviors and their use of alternatives to suspensions was limited.

\section{Challenges of Implementation}

One of the greatest challenges most school districts will face in the implementation of restorative justice is simply having the courage to break away from the traditional school discipline models; detentions, suspensions, and expulsions. Over the past several decades, schools have increasingly replied upon these responses to address a wide range of student infractions of school rules and norms (Soto-Vigil Koon, 2013). Since the early 1970s, that national suspension rate has more than doubled, rising from $3.7 \%$ of students in 1973 , to $7.4 \%$ in 2010 (Losen \& Gillespie, 2012). This is equivalent to over three-million children in a given year, enough to fill every Major League Baseball ballpark, and every National Football League stadium in the nation, combined (Losen \& Gillespie, 2012). Once a school is able to eventually break away from this entrenched thinking, school leaders must prepare themselves for the difficult task of inspiring and educating others to support the overall effort. Given the limited amount of time and resources available for staff development, not to mention the competing 
priorities of high-stakes testing accountability and critical learning standards, school leaders must model the restorative justice practice in a consistently patient manner (Wachtel, 2013). The shortage of time not only refers to the amount of time available in the school day to effectively deal with conflict in a restorative manner, but also the amount of time available for training staff. While some school systems have devoted institute days and professional development time to such training, many schools, and usually those that need the training most, do not have the funding for such programmatic efforts. While some key staff members can serve as a driving force behind such school-wide change, the task can become overwhelming, and will often lead to burnout and failure. Therefore, reaching the wider school community can prove difficult.

Resistance to a restorative justice philosophy is to be expected, as many veteran teachers will simply view this as the next "flavor of the month," something that will go away given time. Others will argue that this approach is far too lenient on students, and that the offender is getting off easy. In Implementing Restorative Justice, authors Jessica Ashley and Kimberly Burke (2009) provide several recommendations for implementation and sustainability of restorative justice in schools:

- Offering professional development in restorative justice philosophy and practices for all staff, including those not in a teaching role.

- Developing and maintaining a cohort of highly skilled facilitators.

- Using restorative processes to deal with incidents of inappropriate behavior and highlevel conflict.

- Supporting the restorative justice philosophy and practice through teacher education.

- Developing state and school policies that include restorative justice. 
Undoubtedly, restorative programs will take more time to develop and integrate into the school culture versus traditional actions. And while this time-consuming process may seem overwhelming, it is designed to ultimately save time through a proactive approach that prevents and diffuses problems before they occur.

While restorative practices never claim to fully eliminate conflict in schools, they do provide a meaningful response to the individuals involved. This is a response that young adults certainly deserve to have, and one that educational systems have a responsibility to provide. Bruce Schenk (2007), Director of the International Institute of Restorative Practices states simply: "Good relationships are the basis for learning. Anything that affects relationships, like inappropriate behavior, impacts learning. Challenging inappropriate behavior needs to be experienced as an opportunity for learning".

Conceptually, the restorative justice paradigm begins with the notion that crime is an act against people and a violation of relationships as well as the breaking of the law (Zehr, 1990). By contrast, traditional models of community justice served offenders with punishments and left victims without closure. Restorative justice has become a framework for thinking about ways of actually humanizing justice, or bringing victims and offenders together in ways that provide opportunity for the victims to receive explanation and reparation, and for offenders to be accountable for their actions. This includes involving community members meaningfully in helping repair the wrong done to their neighborhoods (Umbreit, Coates \& Vos, 2002).

The restorative justice philosophy exists in stark contrast to the punitive methods used for addressing student wrongdoing; methods still widely followed throughout the present-day educational system. Arguably, these dated approaches more closely resemble the current criminal justice system; a formally rigid and retributive attitude designed to ensure public safety. 
Schools that adopt restorative discipline approaches are modeling the values of a socially responsible learning environment where all students are valued and listened to. Disciplinary reform efforts should strive to create learning environments that blend both a student's feelings of safety and respect (Fein, 2002). Amstutz and Mullet (2005) summarize this point by stating that: "[restorative practice] focuses on helping students understand the real harm done by their misbehavior, to take responsibility for the behavior, and to commit to positive change" (p. 21). Although it would be naïve to assume that a single restorative conference or mediation will change the behavioral mindset of problematic youth, the restorative philosophy has been shown to improve overall school climate (Cameron \& Thorsborne, 2001; Reistenberg, 2006; Summer et al., 2010). 


\section{CHAPTER III: METHODOLOGY}

The purpose of this research study is to examine the work of three disciplinary deans as they review current practices, and examine the potential impact of a restorative model in a large suburban high school. The school, Northwestern High School has used punitive disciplinary models for addressing issues of student wrongdoing in the past, but has begun to implement more restorative practices. Insights into this process have been revealed by gathering evidence from the lived experiences of the individuals involved. Ethnographic research data will be presented that captures the essence of what this team will work through; their struggles, apprehensions and those unique "ah-ha" moments. Data presented from this dissertation will represent the voices of those staff members directly involved in one restorative justice initiative.

This dissertation will also help develop a broader understanding of the overall implementation process from the collaborative perspective of those individuals involved. Research will include the review of current disciplinary practices and follow-up discussions regarding alternative approaches through a restorative justice model.

\section{Research Design}

All research designs can be discussed in terms of their strengths and limitations in directing a researcher toward desired findings. Selecting one particular design over another is generally a decision based upon the research problem; what it is the researcher is specifically looking to examine or learn (Hancock \& Algozzine, 2006). This study used the Action Research methodology in order to make sense of, and gain new knowledge from, the in-depth examination of a school leadership team as they rethink traditional discipline practices and give consideration towards the restorative justice model. 
The action research methodology helped to refine the approach being used in the development and implementation of a restorative discipline model in the high school setting. Herr and Anderson (2005) refer to action research as having the 'double burden;' reference to there being the need for both action (improvement of practice, social change and the like) and research (creating valid knowledge about the practice) in order have relevance. Action research is particularly useful for the researcher/practitioner seeking an opportunity to improve upon practice. Action research is often used when there presents an opportunity to address a specific problem within a specific setting, while maintaining an interest in improving quality and creating social change (Merriam, 2009).

Action research became an established methodology since its methods were future oriented, collaborative, agnostic, and situational, while its success rests on understanding the value of how a problem is solved and appreciated during the process (Susman \& Evered, 1978). More specific to this research study, there are opportunities within the action research model to bring about change, and at the same time develop a new understanding of what informs change and how the process can be improved for others as they review school discipline practices and give thoughtful consideration to the restorative alternative.

\section{Historical Perspectives and Use in Education}

Stephen Corey at Teachers College at Columbia University was among the first to use action research in the field of education, believing it would bring about change because the teacher was involved with both research and application of information (Ferrance, 2000). Corey (1953) would state more directly: "We are convinced that the disposition to study...the consequences of our own teaching is more likely to change and improve our practices than is reading about what someone else has discovered of his teaching” (p. 70). 
Corey (1953) believed that the value of action research is in the change that occurs in everyday practice rather than the generalizations to a broader audience. He saw the need for teachers and researchers to work together (Ferrance, 2000), which was supported in the work of Heidi Watts (1985) in which she states that action research is based on the following assumptions:

- Teachers and principals work best on problems they have identified for themselves.

- Teachers and principals become more effective when encouraged to examine and assess their own work and then consider ways of working differently.

- Teachers and principals help each other by working collaboratively. Working with colleagues helps teachers and principals in their professional development. (p. 118)

It is ultimately understood that action research is inquiry that is done by or with insiders to an organization or community, but never to or on them (Herr \& Anderson, 2005). Therefore, action research serves as a compelling tool to create positive change within an organization. The approach is forward-thinking in nature and seeks to engage others in critical thinking and professional dialogue in a collaborative setting that is solution-oriented.

\section{Participatory Action Research}

The participatory nature of the research I will employ is the Participatory Action Research (PAR) method. PAR combines systematic research with the development of practical intervention (Dold \& Champman, 2012). Members of a research study will be directly affected by the phenomena being studied, leading to more interest and a willingness to immerse themselves in the discussions and decision-making process. Phillips, Berg, Rodriguez, and Morgan (2010) further explain that PAR uses a participatory inquiry and action approach to engage participants in identifying and addressing issues, designing and conducting research on 
those issues, analyzing the results and findings, working to resolve social problems that affect them, their peers, or the agencies that serve them, addressing the policies that affect them, and their communities, and then reviewing the results and the research process.

The action research methodology specifically provides the opportunity for me, as the researcher, to work closely and collaboratively with my colleagues, as well as to learn from the process and change my own individual leadership practices in the future. Action Research is reflective in nature, and will therefore provide regular opportunities to critique the process, make adjustments, and reevaluate. This will provide a natural opportunity to move between action, and critical reflection, throughout.

Somewhat unique to this research study, an action research methodology also serves to educate people about the restorative justice philosophy, which is largely unknown, especially in the educational setting. According to Merriam (1988), "Research focused on discovery, insight, and understanding from the perspectives of those being studied offers the greatest promise of making significant contributions to the knowledge base and practice of education" (p. 3). This immersion into knowledge provides a level of participant perspective that few traditional research methods can replicate. Herr and Anderson (2005) take this a step further by describing how action researchers must think about what knowledge they have generated that can be fed back into the setting (local knowledge), but also what knowledge they have generated that is transferable to other settings (public knowledge). This research study provides opportunities for both. Members of the research study will present local knowledge more formally to their professional colleagues, whereas public knowledge opportunities are likely to develop as neighboring districts begin seeking similar, alternative discipline models. 


\section{Research Questions}

An action research method was employed in order to describe phenomenological elements of the restorative justice model being implemented at a large suburban high school, lending voice to the work being done by student deans as they rethink traditional methods of discipline. The following research questions guided the data collection and analysis:

1. What is general feeling of our staff when considering the effectiveness of our current discipline practices and how they impact school culture?

2. What preconceived notions exist about the implementation of a restorative justice model at Northwestern High School?

3. What elements of concern or trepidation may exist in the development and implementation of a restorative justice model?

4. How might the implementation of a restorative justice model change student-student and student-teacher relationships at Northwestern High School?

5. In what other ways might the learning environment may be impacted by the implementation of a restorative justice model at Northwestern High School?

The research questions will provide insight into the lived experiences (positive or negative) of individuals directly involved with the implementation of a restorative discipline model.

\section{Research Site}

This research study will be conducted in a large suburban high school setting located in the northwest suburbs of Chicago, Illinois. The district serves approximately 9,000 students between kindergarten and grade 12, the high school alone accommodating 3,000+ students and over 300 certified and non-certified staff. School leadership consists of one principal, three associate principals and academic department chairs. Within the Student Services Division, 
there are 11 guidance counselors, including two counselors dedicated solely to college and career preparation, three deans, three social workers, three school psychologists and one school resource officer.

The school district prides itself on outstanding academic, athletic, fine and performing arts, and co-curricular achievement that has been recognized nationally and throughout the state. The school has a 97\% graduation rate, and 96\% of students attend college after high school. Per pupil instructional spending is over $\$ 10,000$, with operational costs exceeding $\$ 17,000$ per student. Athletic programs are traditionally among the state's elite, with fine and performing arts programs often touting performances at places such as the White House and Carnegie Hall, as well as graduates that will continue their training at prestigious locations such as the Julliard School and New York University.

The community served is socioeconomically affluent, although growing trends indicate that more and more students are coming into the district from areas of lower socioeconomic status, which takes into consideration a person's work experience, educational attainment and family economic and social position in relation to others. The school demographics are currently $83 \%$ white/non-Hispanic with less than $2 \%$ qualifying for English Language Learning support. The city itself is primarily residential, and parents are highly supportive of the administration and the learning environment. The district recently completed a One To World initiative in which all students have either MacBook Air (high school) or an iPad (middle and elementary school). Efforts are moving forward to create blended learning opportunities for students, with $40 \%$ of current courses being at the Honors or Advanced Placement level.

Prior to the commencement of any fieldwork at this location, district administration agreed to the confidentiality requirements relating to the research study data and findings, and 
the limitations on the disclosure of the identities of the participants and organization. For reasons of confidentiality, the research site and participant information will remain anonymous; pseudonyms will be assigned to each.

\section{Participant Recruitment and Selection}

This research study was initiated given my personal interest in the topic of restorative justice. And while my early attempts to implement the restorative model failed, that failure ignited even more interest in finding the right approach to construct a meaningful alternative to traditional discipline practices. Interestingly, in 2015, before a well-developed research plan related to doctoral study was outlined, the Illinois House of Representatives passed Senate Bill 100 (SB 100). This bill is designed to eliminate the programmed suspension and expulsion practices often associated with zero-tolerance policies. According to a 2014 report from the United States Department of Education Office of Civil Rights, Illinois has one of the widest disparities in the nation between suspended black students and their white classmates. During the 2013-14 school year, Chicago Public Schools issues suspension for 32 of every 100 black students, compared to just five of every 100 white students (United States Department of Education Office of Civil Rights, 2014a). Under the new law, which went into effect in September of 2016, suspended students were provided greater academic and social-emotional

support from counselors and mental health professionals. Improved communication to families, with more detailed explanations of the rationale for suspension, is also part of the SB 100 guidelines.

Senate Bill 100 will require sweeping changes to the traditionally punitive discipline practices used in schools. For that reason, the deans and I orchestrated a thorough examination of current discipline practices at Northwestern High School. Together, we identified 
disproportionate school exclusion practices for minority students, an antiquated referral process, and how current practices were having a negative impact on school culture. We also engaged in research and conversation related to alternative discipline options and how these ideas could be successfully implemented. More importantly, there was a level of trust being built between myself and the deans during this time. The mutual respect was rooted in our shared experiences in school discipline, and although my administrative role oversees these positions, an understanding of the daily trials and tribulations of this role was made evident. The deans position address all disciplinary events at the high school, ranging from chronic absenteeism and truancy, to more significant behavioral issues like the illegal use or possession of a controlled substance on school property, harassment, and fighting. These roles were directly identified given their day-to-day experiences, knowledge and expertise.

These individuals were selected through purposive homogenous sampling as the research is specific to the characteristics shared by each member. Each individual shares the responsibilities of the Dean role within the Student Services division at Northwestern High School. Based on the size of the school, the total number of faculty members, and the timeframe of which to conduct the study, it was not feasible to collect data from a larger population. In addition, a study's participants should have direct experiences with the phenomenon that is being studied in ways that will allow them to convey evocative descriptions and explanations (Creswell, 2007).

Participants were informed of the research study during a weekly meeting held at the school. The goals and objectives of the research study were presented, outlining the specific details related to their potential involvement. Potential participants were also afforded an opportunity to speak with me privately in order to ask additional questions or inquire further into 
the research study. A concerted effort is made to ensure that participant identities remain anonymous and that all recorded responses are represented accurately.

All participants involved are adults; no contact will be made with any person who is currently, or was at the time of the research, a minor. Participants in this research study are physically located in the same general area of the high school, and elected to have the regularly scheduled meetings in a co-curricular conference room located within close proximity to their offices. This location provides privacy, yet is easily accessible by administrative assistants should there be an immediate need to contact a Dean for assistance. Meetings took place between Monday and Friday, during regular school hours. Meetings were not mandatory, and individual participants were free to stop participation at any time without penalty or loss of privilege. It is worthy to note that, given the size of the sampling, I will know each prospective participant.

\section{The Research Participants}

The information retrieved from countless observations, formal and informal interviews, and group discussions have come from four specific individuals, the student deans of a large suburban high school and an associate principal. Throughout the research I've found that individual input was heartfelt, often directed poignantly through a variety of emotions; immense frustration, as well as humor and humility. What I came to appreciate most was the reflective nature of the work.

For instance, a question commonly asked at the close of each group and individual interview was, "Are there any additional thoughts, ideas or questions that you would like to share?" The reply, more often than not, was posed as a question back to the group - this would become the deans' opportunity to run a self-check, comparing how they may have handled a 
situation in comparison to their peers. This generally led to some unique banter that can best be described as a non-judgmental 'I've been there before' conversation. This served as useful time to gather insight into how the deans treated one another in relation to their respective practices. I was able to gain insight into the ongoing checks-and-balances that took place in the discipline office. It also provided me insight into how each dean had his or her own unique approach to discipline.

\section{Meet the Participants}

The first participant in this research study is myself, the researcher. This is my second year as the Associate Principal for Student Wellness and Operations at Northwestern High School. This position is primarily responsible for the oversight and coordination of the counseling department, special education department, and the dean's office. In addition, I manage general building operations related to the physical learning environment.

Heath. The researcher. "Okay, let's talk about this...how can we make this a better school environment for everyone?"

I served as the Dean of Students in another district, prior to my current role as Associate Principal for Student Wellness and Operations at Northwestern High School, where I have been for the past two years. While my lens for the development and vision of school operations has expanded, my natural interest in student discipline practices remains a personal passion. That being said, the bond between myself and the deans has always been a strong one. Over the past two years I have helped to develop and support proactive intervention programs aimed towards at-risk youth.

My primary approach to the research has been to ask the simple, yet sometimes difficult questions. I often started conversations with "why?" in seeking to better understand the rationale 
behind certain decisions. The deans quickly came to learn that my least favorite response to any question type, was with the all too familiar, "well, that's just the way we've always done it." In response, there became a running joke among all participants that any time a long-standing approach or response of this nature was given, they knew I would respond in my best Dr. Phil (Phil McGraw, host of his own life strategies advice show, Dr. Phil) voice "and how's that goin' for you?"

There were also moments throughout the research when the sheer exhaustion of the discipline grind was evident. Throughout, I would serve as a cheerleader of sorts, always in support of the restorative work being done, and often reminding the deans of the important role they each played in reshaping school culture. My own personal leadership style is to empower people; helping others to understand the importance of engaging in the development of something special, beyond just being present. The deans certainly engaged in the implementation of a restorative model process, and more importantly, felt empowered to recommend changes or to question ideas themselves.

On Current Discipline Practices: “We can't keep doing what we've always done in school discipline because the model is broken, it doesn't work, and it's not good for kids and the culture of our school."

On The Restorative Model: "Restorative discipline practices have tremendous upside, so let's dig-in and discover how this will work for us."

The three additional participants in this research study serve as the student deans at Northwestern High School. This position falls into the administrative category, and is therefore considered a non-union position (unlike some school districts in which the dean remains on the teacher contract). Unique to this role, the deans either teach one class, or may carry a small 504 
or IEP caseload of students. In addition, the deans for this research study are also active as coaches and/or club sponsors at the school. While these added layers to the role of a student dean are certainly not unheard of, some school districts may define the scope of a student dean responsibility differently.

Daley. The veteran. "I love my job and hope every day is a good day. The better they [the students] are, the easier my job is."

Daley is a veteran staff member with over 20 years of experience in the high school setting. His primary teaching certificate is in physical education. He is quick to claim his origins as simply Southside Chicago. Daley has served as the dean of students for the past seven years, and continues to serve the school as a club sponsor.

At first impression, Daley comes across as the salty curmudgeon, quick to push back and dispute any new and innovative ideas. Throughout the research, Daley was known to use sarcasm and curt remarks in response to group and individual interview questions. It was evident that these same characteristics made Daley somewhat less popular with the students and staff; especially those that didn't know him well. This exterior persona was, at times, challenging for me to get past during the research, meaning that it was sometimes difficult to determine the seriousness of his comments. However, through time, Daley proved far more complex and insightful than his original façade would project. As the research expanded, and his comfort level grew, so too did his willingness to share more directly and openly.

It was during individual interviews and office observations that I was most struck with Daley's depth of knowledge, care, and genuine concern for the well-being of students. Although there were clear boundaries and a somewhat methodical level of consistency to his approach, students never seemed anxious or at edge when in his office. "I think students know that I'm 
going to be fair and consistent every time I see them," he replied shortly after a routine visit with a student regarding truancy.

On Current Discipline Practices: "Look, I'm old-school, maybe a little too much, but I do understand that something probably needs to change. These kids are different. I can see that a lot of what we've been doing [in discipline] isn't working like it did."

On The Restorative Model: “.... a little too touchy-feely for me, it’s like every kid just needs a hug. But I get it, it's [restorative discipline] something new that the district wants to try."

Richard. The utility infielder, willing to take on anything thrown his direction. "Just tell me what you want me to do, and I'll do it. If that means I need to break the mold or whatever, fine. I'm willing to try whatever until I find something that works."

Richard loves thinking about school discipline. He is eager to engage in the research, and talks passionately about student issues that he encounters along the way. Like Daley, Richard also has over twenty years of experience in the high school setting. However, only four of these years are in the role of student dean. Richard holds certification to teach English, and also serves as an assistant coach in the school.

Richard is a fast moving, always on-the-go type dean. One minute he will be in the office, next he's addressing three separate issues between the cafeteria, a hallway, and the library. When provided with any tips, or needed details on a disciplinary issue, Richard is quick to respond personally, often walking directly to the classroom in order to expedite any necessary conversations. "I like to give them [the student] a heads-up...kind of breaks-the-ice before we get to my office." 
Richard is easily the most popular of the three deans. If there is a line in the dean's office, students are often there to see Richard, and often by choice. Although interviewing students was not specific to the design of this research, my intuition tells me that students are drawn to Richard's naturally energetic demeanor and 'cool' mannerisms. As an example, students are assigned to a particular dean alphabetically by last name, and Richard easily has more 'crossover' than the others, which means he will also see students designated to a different dean based on name, simply because kids find him to more appealing or approachable.

"I can be a little fiery when I talk with kids, they probably think I'm crazy, but I try not to talk down to them or make it seem like they can't talk to me," he quipped shortly after a conversation with a female student that ended with her laughing as she walked out of the office.

On Current Discipline Practices: "I'm not really sure...well I like to think that I've already moved away from that [current practices]."

On The Restorative Model: “I don't really think of naming what I do, but it's probably something I'm hopefully doing...I guess there's more of a name for it."

Maggie. The mother hen. "I take care of just about everything down here anyway, as well as keeping those two (points across the table) in-line [laughing]."

Maggie easily has the burden of being considered the lead-dean. Although not identified as such by title or compensation, Maggie represents the dean's office on several school and district level committees, often reporting data or other pertinent details as requested. Although Maggie has fewer years of experience in education overall, she has been in the role of dean longer than her two counterparts. Maggie is a certified special education teacher and also serves as the Key Club sponsor, a service leadership and character-building program that is linked to a local Kiwanis Club. 
In short, Maggie appears exhausted. While complaints directly from her are far and few between, you get the sense she's simply fatigued from the daily grind of school discipline. "This job takes a lot out of you, it sucks your energy sometimes, and ya, I hate to even say it, but it's tiring." One specific job duty that is assigned to Maggie is working with our attendance office personnel. This portion of her role requires a great deal of time and energy as she helps troubleshoot attendance related issues with staff almost daily. Maggie also finds that because she is the only female in the dean's office, staff members will often seek her first when there exists the need to report a dress code violation of a female student.

Maggie is very knowledgeable when it comes to the day-to-day procedural aspects of not only her job, but also what teachers need to be doing as well. She voices frustration when seeing discipline referrals from specific teachers, believing that they [the teacher] likely 'fueled the fire' over what she would believe to be a trivial issue. Maggie's sense of humor and sporadically jovial nature conflicts with the sometimes-dogged feeling she projects outwardly. Regardless, Maggie does appear to have a good pulse for the building as it relates to school discipline. More specifically, Maggie has a sense for how staff members in general will react to the handling of particular situations... usually. "I try and head-off complaints like that, but that's one I didn't see coming. Oh well, another unhappy customer," Maggie would mutter with a slight laugh as a frustrated staff member leaves her office.

On Current Discipline Practices: “I just worry that we [the deans] won't be as consistent with things...teachers will question that. What we've done with discipline over the years has been really good." 
On The Restorative Model: "I think it's great... and something I wish teachers knew more about too. They [the teachers] could maybe do a lot more of the problem-solving in their own classrooms instead of sending them to us [the dean's office]."

Each participant brought his or her own unique personality forward during the research study. And, as trust and interest grew, so did my presence within each of their offices at various times throughout the research. I was particularly pleased when events were taking place that would be of specific interest to this research study, and I would be contacted directly to observe as the restorative conversations unfolded. Admittedly, there were times during the research, especially early on, where I felt as though conversations seemed too canned and unnatural. I reminded research participants early, and often, that the most meaningful research would come from their true emotion, and not from what they think I may need, or want to hear. Within a short period of time, this early trepidation would change to an openly cooperative, trusting and jovial nature from the deans, with any sense of skepticism virtually erased.

Group interviews clearly evolved into time for the deans to debrief with one another. Although questions specific to the research study were presented, conversations often circled back to recent events, how they were handled, and what thoughts the team had. I quickly learned that having time together, as a team, was sorely lacking unless scheduled. This lack of time to review discipline practices would become an unforeseen dynamic to the research that I would capture. Group interviews were also far more honest than I expected, making it clear to me that the research participants were comfortable sharing with one another present. Richard, for example, slumped into his chair during an impromptu meeting with Daley, and opened with, "I sucked today." Richard would go on to share how we would "lose his cool," with a student, and 
simply sent them to in-school-suspension without much of a conversation, "I was just done man."

I came to find that these types of conversations, largely unstructured and unplanned, would serve as the most authentic. Although individual conversations lacked the more relaxed and loosely worded response moments, they were helpful in bringing more thoughtful layer of understanding to the research. Individual interviews felt more scripted, and although there was a freedom to discuss anything related to the research, participant responses were on-point to any posed questions, and rarely strayed into other areas without prompting. One adjustment I made in an effort to provide a more natural starting point for the individual interviews was to use a recent discipline event as a point of focus. This provided a framework of which I could weave other research questions in to.

My goal, regardless of group, individual or impromptu interviews or observations, was to give voice to the daily work of the Deans at Northwestern High School. Capturing everything between their moments of calm insight, to obvious frustration, provided greater understanding of what schools will face when implementing the restorative discipline model.

\section{Data Collection Methods}

Data collection took place during an eight-week period in the fall of 2016. Northwestern High School is forward thinking in many academic areas, but somewhat antiquated in their approach to school discipline practices. Several candid discussions throughout the prior school year fueled interest in moving the high school forward in the review of current discipline practices, as well as consideration of the restorative model alternative. The natural interest of many staff members within Student Services, as well as the support from school and district level administration, has been a motivating factor in furthering the research study. 
Data gathering techniques throughout the research study included explicit permission from the active participants, and is in full compliance with Internal Review Board (IRB) guidelines. Participants were also provided with a detailed written transcript of the recorded conversation for their personal review ahead of any published account. Prior to publication of the research, participants were asked directly for approval of accuracy.

The study utilized semi-structured focus-group interviews, semi-structured individual interviews, and review/analysis of two surveys; the 5-Essentials survey and a participant perception survey.

\section{Focus Group Interviews}

According to Bloom and Crabtree (2006), "Qualitative interviews have been categorized in a variety of ways, with many contemporary texts loosely differentiating qualitative interviews as structured, semi-structured, and unstructured" (p. 134). These focus group meetings are semistructured. Semi-structured interviews are organized around a set of predetermined, open-ended questions, with other questions emerging from the dialogue between interviewer and interviewee (Roulston, 2010). The questions are focused on the content of the research study and will include both closed and open-ended questions in order to provide participant flexibility.

Focus group interviews served as the primary source of data to inform this research. Focus groups meetings had a consistent agenda format that included opportunities to openly discuss current issues, as well as to follow-up on issues from previous meetings. In addition, data related to school discipline practices and the restorative alternatives being used were discussed. The opportunity for open dialogue among the group provided rich insight into the emotions and feelings individuals were having in relation to the development of restorative discipline practices. 
Data was electronically recorded on a personal device that is passcode protected. All issues related to safety and security of these conversations will be in full compliance with Internal Review Board (IRB) guidelines.

\section{Individual Interviews}

By using a semi-structured interview format, I will have an opportunity to gather data that may not be otherwise shared in a larger group setting. During individual interviews, I am able to more closely examine the knowledge and procedural perceptions of individual participants. Participants are also more likely to share as much information as possible, and in their own words. Probing questions will be used throughout the interview to keep the participant talking, and on-track, in an effort to stimulate thinking and ultimately generate more data.

For convenience, all interviews will be held in participants' offices, and will last between 30-45 minutes. Data will be electronically recorded on a personal device that is passcode protected. All issues related to safety and security of these conversations will be in full compliance with Internal Review Board (IRB) guidelines.

\section{Participant Perception Survey}

The participant perception survey will serve as a research instrument consisting of a series of questions for the purpose of collecting facts, perspectives, attitudes and/or values from participants as they relate to school discipline and the restorative justice model. The survey will be provided to all participants at the first meeting, and again at the last meeting.

Data related to the perception surveys will provide insight into any personal change a research participant may have in relation to their feelings or perceptions of restorative practices. This information will serve as a helpful tool during follow-up interviews in order to further investigate the reasons for any change in attitude, thought or perception. 


\section{Analysis of Data}

The first step in my analysis of the collected data was to begin breaking down the research into emerging themes. Through and open coding approach I was able to provide a descriptive 'name' to specific elements of the data, which helped to identify patterns of overlapping information from the participants.

There are three sources of data that are being analyzed as part of this research study. The first, and primary source of data will be derived from the semi-structured focus group interviews. This format is flexible and will provide latitude for me to ask questions that were not predetermined in an effort to direct conversations toward new ideas or information not previously thought of.

The second source of data was derived from individual interviews. These conversations provided participants with an opportunity to respond in ways they may not have been natural for them in the group setting. Both interview formats involved the transcribing of recorded conversations. Given the sheer volume of research to be analyzed, actual data analysis began immediately following the first interview. This was done in an effort to begin identifying patterns of data that could be coded and categorized, as well as being useful in facilitating subsequent group, and/or personal interview questions. Stake (1995) reminds the researcher "there is no particular moment when data analysis begins. Analysis essentially means taking something apart" (p. 49).

With specific consideration to this research study, the lived experiences of each participant were 'taken apart' through and in-depth review and comparison of recorded transcripts, field notes, and personal conversations that took place throughout the research timeline. By reviewing data, I am able to more accurately tell a collective story about the 
procedural efforts necessary to rethink, and ultimately redesign, a school discipline process. Outside of the scheduled focus group interviews, opportunities to collect data often occurred shortly after a disciplinary event was complete, or while the event was actually taking place. Often, I was invited to join conversations related to issues "in-progress." These moments provided me direct insight into the thoughtful decision-making that goes into various discipline events. My intention was to bring forward a rich portrayal of the data that has emerged throughout the study timeline by examining the notes, along with other group and individual interviews, this, in order to draw connections between words and actions from the research participant.

The final piece of data analysis came from a general perception survey given to each research participant on the first meeting date. These responses were used to simply better understand participant attitudes toward current practice, and the proposed restorative model, as well as offering a sense of direction when structuring focus-group and individual interviews. Perceptions, like attitudes, are important to understand as part of the research because they have the potential to predict certain behaviors from the participants. If perceptions about the implementation of a restorative discipline model are weak, that participant may be more likely to take shortcuts in their approach, or default to traditional discipline methods for reasons of comfort or convenience.

The perception survey was analyzed using a five-point Likert scale in order to rate the degree to which an individual may agree or disagree with a specific statement related to school discipline practices and the restorative model. I was also intrigued by the differences of opinion between the participants, as well as any inconsistencies between their words and actions. 


\section{Triangulation}

McMillan and Schumacher (2010) defined research triangulation as a "cross-validation among multiple data sources, data collection strategies, time periods and theoretical schemes" (p. 491). Triangulation of multiple data sources is completed to ensure reasonable validity (the information is accurately represented) and reliability (the research is accurate). Sagor (1992) uniquely describes triangulation as observing a phenomenon through multiple 'windows,' which can allow a single researcher to compare and contrast what is being seen through a variety of lenses.

This research study will triangulate data related to current discipline practices and the implementation process of a restorative model. This will be accomplished through focus group interviews, individual interviews, field notes collected throughout the research, as well as perception surveys given to each participant prior to research taking place, as well as after. I will be able to draw upon the amassed evidence to either corroborate, or potentially contradict, what participants share with me verbally and what their actions may indicate.

\section{Ethical Considerations}

Ethical issues enter into every phase of an action research dissertation, from the design to the actual execution of the proposal to the representation and dissemination of the data (Herr \& Anderson, 2005). Efforts were made throughout the various stages of planning, participant solicitation, research, data analysis and final presentation, to anticipate any potential issues that participants may encounter. This research study did not pose more than minimal risk to the participating members. All participants in the research study were adults, and no identifying information was used in the data collection. Each participant in the research will sign informed 
consent forms prior to his or her involvement, all within full compliance of the established Internal Review Board guidelines.

Because action research is a dynamic, evolving practice, there is no foolproof plan to avoid ethical dilemmas as the research develops (Herr \& Anderson, 2005). Cassell (1982, as cited in Herr \& Anderson, 2005), suggests that:

perhaps most important to the process is the ability to recognize an ethical issue when it arises so that it can be taken into consideration; the work, then, is not to anticipate every possible ethical conundrum as much as to commit to addressing them as they arise. (p.

While no issues related to ethics are anticipated, it is possible that individuals involved in the research feel as though their observed actions are being evaluated given my position as Associate Principal. In the hierarchy of this educational setting, the Dean of Students position is subordinate to my role. Given my disciplinary work experience in a neighboring district prior to coming to Northwestern High School, the Deans and I already formed a trusting relationship that encourages questioning and dialogue about discipline practices. Other efforts to minimize coercion included using third-party individuals for communication, collection of consent forms, and scheduling. No incentives were provided to research participants, and each individual was made aware of their rights to participate or not participate in the study without penalty.

\section{Research Limitations}

This research study is limited to Northwestern High School, a large school setting located in one particular school district in Illinois. It does not take into consideration the unique nuances other individual districts may face. For example, the participants in the study were purposively selected given their role. Therefore, these individuals may be naturally more interested in 
engaging and thinking in greater detail about issues related to student discipline, and the social/emotional impact of punitive versus restorative practice.

The timeframe of the research study was limited to 8-weeks in an effort to provide time for data review and final written analysis. Allowing for more research time may provide greater insight into the level of success (or lack thereof) various restorative practices has on students, thus offering greater support for (or against) such implementation.

Measuring school climate during this short time span is difficult. However, the research does point to the development of more meaningful relationships between students and staff/administration. Participants in the research are also able to articulate the feelings that students and staff are sharing as a result of restorative practices. When restorative practices are found to have fostered a more meaningful relationship for everyone involved, versus previous practice, it can be assumed that these sentiments will have a positive impact of school culture.

Design methods are often described, and ultimately selected, based on their strengths and limitations in directing a researcher towards desired findings. Although there are a number of qualitative design methods available, selecting one over another is generally a decision that is based upon the research problem; what the researcher is looking for. According to Merriam (1988), "Research focused on discovery, insight and understanding from the perspectives of those being studied offers the greatest promise of making significant contributions to the knowledge base and practice of education" (p. 3). Therefore, the research methodology for studying the implementation process of a restorative discipline model lends itself to participative action research.

This "learning by doing" approach brings together a group of like-minded people that have identified a problem and are doing something to resolve it. Their lived experiences are the 
basis of this research, with key findings based upon the detailed experiences, perspectives and viewpoints from the individuals involved. The richness of data, often sought in qualitative research, is found through the personal relationships that are formed throughout the process. There are also opportunities to review relative documents produced as part of the overall process; referral data, participant statements/reflections, and perspective surveys. Gilmore, Krantz and Ramierz (1986) provide this as a more succinct definition:

Action research aims to contribute both to the practical concerns of people in an immediate problematic situation and to further the goals of social science simultaneously. Thus, there is a dual commitment in action research to study a system and concurrently to collaborate with members of the system in changing it in what is together regarded as a desirable direction. Accomplishing this twin goal requires the active collaboration of researcher and client, and thus it stresses the importance of co-learning as a primary aspect of the research process. (p. 161)

Furthermore, in qualitative research studies, developing central research questions and subquestions usually focus on discovery of the "why" and "how" of a phenomenon, event or program. The action research methodology will allow the researcher to immerse into the process and extract key elements of knowledge that can be used to guide others through a similar process, thus providing a contribution to the field of study, as this research will allow others to make informed decision when considering similar change or enhancements to school discipline practices. 


\section{Definition of Terms}

Administrator - Throughout the scope of this research study, the term administrator refers to a school principal, assistant principal, dean, or other figure with policy making decisions.

Culture - The shared, learned beliefs, material products, and social actions that characterize a social group (Angrosino, 2007).

Expulsion - The act of removing students from the learning environment. This differs from suspension in that the removal due to expulsion may become permanent (Morrison \& Skiba, 2001).

Instructional Time - Refers to actual time spent in an academic setting where direct instruction is taking place. This includes formal and informal learning opportunities and alternative classroom arrangements such as a tutor center, resource/media center, or library. Students that are suspended from school or the classroom setting, essentially lose the right to teacher instruction.

Punitive - Refers to disciplinary action that is traditionally reactive to wrongdoing; assigning consequences with little to no consideration Recidivism - The recurrence of problematic behavior in an offender. Recidivism rates refer to the frequency at which an individual repeats unwanted behavior despite intervention. Restorative Discipline - A disciplinary approach that seeks the reparation of harm between individuals after an incident of wrongdoing. The restorative nature of school discipline may include, but is not limited to, conferencing, circles, peer juries, and mediation. This term is often used interchangeably with Restorative Justice. 
Restorative Justice - Philosophy based on the view that conflict or harm affects individuals and their relationships with each other and society (Braithwaite, 2002). Restorative justice allows individuals experiencing conflict to come together to resolve issues, work to repair damaged relationships, and deal with the consequences of conflict (Zehr, 2002).

Retributive Justice - A system of thought that focuses attention on punishment and consequences after wrongdoing, rather than reparation or rehabilitation.

Saturation - In qualitative research, the point in continuous data collection that signals little need to continue because additional data will serve only to confirm and emerging understanding (Merriam, 2009).

School-to-Prison Pipeline - Policies and practices that push our nation's school children, especially our most at-risk children, out of the classroom and into the juvenile and criminal justice system (American Civil Liberties Union, 2012).

Stakeholders - Individuals that are invested in the welfare and success of schools and the students being served. This includes, but is not limited to, school administrators, teachers, staff members, parents, community members, business leaders and elected officials.

Suspension - The act of removing a student from the school setting for a specified period of time in response to inappropriate behavior.

Triangulation - In order to increase trust and validity of qualitative research data, multiple data sources and collection procedures are utilized in order to evaluate the extent to which all evidence converges (Merriam, 2009)

Zero-Tolerance - In the school setting, zero-tolerance refers to a policy for punishing any infraction or rule, regardless of accidental mistakes, ignorance, or other extenuating circumstances. Very little regard is given to the individual offender, and circumstances are 
traditionally viewed as harsh and swift. "Policies that punish all offenses severely, no matter how minor" (Skiba \& Peterson, 1999, p. 372). 


\section{CHAPTER IV: RESEARCH RESULTS}

The focus of this research study was to examine the implementation process and impact of a restorative justice model in a large suburban high school setting. Through the use of small group and individual interviews, as well as observations and field notes, I was able to gain rich insight into the lived experience of three student deans. These interactions allowed me to capture the essence of what an implementation process looks and feels like, as well as what potential impact the restorative model has on school culture.

All research took place during regular school hours between October 14, 2016 to February 10, 2017. While participants contributed differing amounts of information given personal interest in a specific research question or discussion topic, all voices and views were represented in this study.

The following research questions informed this study:

1. What is the general feeling of our staff when considering the effectiveness of current discipline practices and how they impact school culture?

2. What preconceived notions exist about the implementation of a restorative justice model at Northwestern High School?

3. How might the implementation of a restorative justice model change student-student and student-teacher relationships at Northwestern High School?

4. What elements of concern or trepidation may exist in the development and implementation of a restorative justice model?

5. In what other ways might the learning environment may be impacted by the implementation of a restorative justice model at Northwestern High School? 
Three distinct themes emerged from the research data. Two of these themes are related to the implementation process of a restorative discipline model, the third theme is related to the impact a restorative discipline model has on participating individuals, and the school culture.

- Theme I: Appearance and Communication. The common perception, or appearance, of the Restorative Discipline model is weak, and does not resemble the traditionally aggressive approach school staff are familiar with. The lack of communication, regarding restorative measures also exacerbates the misunderstandings.

- Theme II: Training and Support. Without the purposeful implementation of a schoolwide restorative training model, discipline responsibilities continue to fall primarily on the shoulders of student deans. Thus, there exists a necessary level of support from key stakeholders in the building.

- Theme III: Developing Relationships. Using the Restorative Discipline model develops important relationships between those involved in the process.

\section{Theme I: Appearance and Communication}

The staff at Northwestern High School has voiced frustration over increased behaviors of disrespect and general non-compliance. Several staff members have made comments that the students no longer 'get in-trouble' or that nothing is done when misbehavior occurs. While some staff members are more understanding, and believe the deans are doing the best they can with limited time and resources, others direct their displeasure more personally; questioning the strength of consequences and the ability to handle situations effectively. One staff member encountered during the research stated simply, “kids just don't have any fear of consequences, they get away with just about everything nowadays." 
The overall sense from staff is that school culture is spiraling downwards, and that a growing lack of respect and ability to effectively control, or deal with misbehavior, is largely to blame. Several behavioral events this school year have fueled these emotions as they've been very visible within the school culture; significant vandalism, physical fighting, drug use, gang graffiti, and destruction of bathroom facilities. Compounding this has been the student attention given to such events, which is often captured and shared on social media.

Many staff members have voiced their concerns on this publically, and while some are eager to be part of the solution, most have resigned to criticisms and indifference.

There exists an appearance that restorative practices do not provide a strong enough consequence, or deterrent, to adequately address student behavior. "Teachers are still looking for that pound of flesh when it comes to disciplining students," remarks Maggie. There is an overwhelming feeling that when a school rule is broken, there needs to be a consequence. And, because these consequences have looked the same for years at Northwestern, teachers have simply grown accustomed to what should happen in response to their referral, giving little, to no consideration on the impact these consequences have had on students. The restorative approach has teachers often asking why we allow students to "get away" with certain behaviors. Comments like this once confused and bothered me. Yet, what I've come to realize is that the calm and more conversational manner of restorative practice gives some individuals the impression that indeed, nothing is actually happening. It's not until they are directly involved in the process, that they come to realize the significant meaning behind the restorative approach.

Take for example the case of Olivia, a junior in high school, whom is no stranger to the discipline office staff. Her daily demeanor can range from a bright and cheerful smile to being downright belligerent and rude. The most recent referral from her science teacher described 
inattentive behavior, an unwillingness to cooperate and ultimately a string of expletives upon being redirected. After tracking her down in the cafeteria a couple of class periods later, Richard would bring her to the office, where a restorative conversation would begin. "In the past, I would have just grabbed her (not physically) and put her 'in-school' for the rest of day. But now...there's got be more to the story." And, indeed there was.

Starting a conversation in the restorative model begins not by asking what the student has done wrong, but inquiring as to who may have been hurt by the described negative behaviors. In doing so, Olivia acknowledged that behavior distracted peers and was disrespectful towards the teacher. At the same time, Richard also provided Olivia with an opportunity to talk about her needs, and what the causes were to bring about such behavior. "That's not something I ever made time for in the past, it's not that I didn't care...but, you know...I really didn't care...does that make sense?" In the past, Richard, like many other administrators, felt the need to show a level of authority - looking beyond the needs of the student, focused on a quick and appropriate punishment. The restorative approach naturally slows down the process, but seeks to ultimately make things right. "Olivia, who do you need to talk with in order to put this to rest, and move on?" Richard would finally ask.

Not all discipline situations lend themselves to the restorative process Richard followed, however, basic principles are applied by using guided questions developed by Howard Zehr (2005):

1. Who has been hurt?

2. What are their needs?

3. Whose obligations are they?

4. What are the causes? 
5. Who has a "stake" in this?

6. What is the appropriate process to involve stakeholders in an effort to put things right?

These questions are designed to stimulate a reflective response in students and place responsibility and ownership of the conflict back in their hands. They also guide discussions and can generate new ideas as to what the student will do to resolve the conflict. While best used in an informal manner, while talking with a student in the office, they can also be more formalized for use in conferencing, or large group discussions where more stakeholders are involved.

Northwestern High School has now been implementing these restorative principles over two years. Primarily, in an effort to keep students in school, versus issuing out-of-school suspensions, as well as in-school suspensions, which also effectively remove the student from an opportunity to learn. From small tweaks, like writing a letter of apology versus issuing a detention, to larger conferences or mediations that may include parents and other stakeholders, the move away from traditional consequences began in earnest this past year. The primary goal was to add restorative measures alongside traditional discipline in an attempt to satisfy the balance between punitive and restorative actions. "We [the deans] knew that Restorative Discipline programs were starting up around us. I think it was CPS (Chicago Public Schools) that created a policy about suspension lengths, so I knew we needed to start changing things here too" Maggie recalls.

One example of this blended approach is the reduction of suspension days for a student found to be under the influence of drugs or alcohol, only if the family agrees to complete an outside drug/alcohol assessment, along with any recommended counseling sessions. Approaches like this are common; a restorative discipline practice is used alongside an existing school 
policy. This blend is undoubtedly a vast improvement over the use of traditionally harsh consequences alone. That being said, there may still be moments when perhaps the traditional methods of discipline still have an impact. Richard would openly share that, "Sometimes I blend the old-school with something like a new practice, because there's a point where the traditional methods still have an impact." Maggie would summarize this comment: "You have certain types of kids...where, if they cut class and get a detention, they're set straight...it won't happen again. We know who those kids are, and we're not focused on those kids with the restorative approach." Although the restorative philosophy aims to make punishment the last resort, and not the first, traditional approaches are still widely used at Northwestern, and done so without hesitation. "I'm not sure what other approach I'd take to a kid being tardy to class? Especially when lunch detentions still work," Daley states. And in many cases, this is true, the loss of social interaction with peers' curbs behavior. Like other large high schools, it's also possible that some automated referrals for events like tardiness are handled by administrative assistants, and not directly with an administrator.

Because restorative discipline is a mindset, and not something applied by to a particular behavioral event, the culture of how we communicate in schools, at all levels, hopefully begins to change. Providing even administrative assistants with the language to help kids understand how being tardy to class has an impact on others within the learning environment. Maggie recognizes that progress, is being made:

I would say, in the beginning, it was a very different feel. The culture was drop the hammer, drop the hammer, drop the hammer. We didn't look at the whole child, the wellbeing of the child. I would say that we've started to shift our practices, all of us, not just in the discipline office. 
This shift in practice isn't without problem. "I still have teachers asking me to change my decision, to just 'suspend' the kid, or kick them out of the classroom," remarks Richard. He would go on to share one particular frustration related to a teacher questioning his methods when returning to the classroom one day after being referred for swearing:

I got an email from a teacher, she's all bent out of shape because I didn't suspend this kid. It's like, 'she might be able to come down and schmooze you, but she can't fool me.' And I'm like 'schmooze?' Really? You have no idea lady...She's homeless. She got kicked out of her house. She's undocumented and scared to death. She's got a lot of shit going on.

One of the strengths of the restorative discipline approach is that it takes into consideration the unique needs of the individuals involved. In this case, and many others like it, the deans have an understanding of the student that a teacher may not. The unintended consequence can make 'discipline' appear to be soft, simply because the approach was sympathetic and not punitive. "What the teacher doesn't know is that the girl needed to see a counselor, not a dean. I get it, but come on, be reasonable," Richard concludes. Although Richard would follow-up with this teacher, and explain the situation more specifically, word about the restorative approach moves slowly, and often in this manner - small pockets, as teachers seek information about a referral, or question an approach.

The discipline policies at Northwestern High School are not restorative by definition, but they do provide for some professional latitude, or flexibility, that allows for a restorative response to take place. And, as the restorative model continues to be more purposefully defined, the deans at Northwestern High School are hopeful that more teachers will begin using this approach as well. "We've never really been given an opportunity to talk about discipline to the staff before, or really event wanted to, for that matter. I guess it was never really seen as all that important. Maybe it is now," Daley would conclude. 
Despite the increased attention given to restorative justice models being adapted for school settings, there remains a stigma from many teachers at Northwestern High School that the restorative discipline approach is weak, and not changing behavior. Therein lies the need for improved communication to be taking place with staff, helping teachers better understand the benefits of a restorative model, and, how these efforts can actually improve the school and classroom environments. "Teachers get pissed when they realize their referral didn't get a student suspended... and that's when they come down and want to talk to me about it," Richard would explain.

Unfortunately, the restorative discipline model at Northwestern High School has never been formally presented to the entire staff, and thus remains a discipline philosophy that is fundamentally unknown to many. Even when presented with an opportunity to learn more about restorative practices during a spring professional development institute, the breakout session titled Understanding the Restorative Discipline Philosophy was attended by only 15 staff members. "Some of those people have never written a referral in their career, come on, that's not the people I wanted to see," remarks Daley laughingly shortly after the presentation. Professional development offerings are still dominated by groups reviewing state and national testing data, departmental assessments, and overall efforts to improve instructional practice. Without a formal platform, introducing the restorative model has resorted to a patchwork effort.

In response to the weak turnout for the institute day, and still knowing there is a real need to provide staff with this philosophical mindset, the deans and I made plans to attend weekly department meetings. This option provided for a smaller audience, and while the time was somewhat limited, the floor was ours. The vast majority of these meetings proved very successful. Staff members were provided a basic working definition of what the restorative 
philosophy is, how it is being applied in the school setting, and even a few meaningful examples. When possible, a restorative response to a behavioral referral from a member of the department we were talking to was used as an example. "It was great having [name removed] confirm that what we were doing actually worked. A lot of people in that department needed to hear that," provided Maggie. Yet in some meetings, the time was quickly consumed with complaints or needs for clarification, as Maggie would also share, "I left feeling frustrated, like they really weren't listening. They really just wanted to ask questions... whether or not they could take a kid's cell phone away, and things like that, it wasn't productive."

Although much more time consuming, even more success is found in communicating the benefits of restorative discipline with teachers individually. This happens most often as a teacher comes into the office in frustration because their referral didn't receive the 'level' of punishment they were hoping for. But when a teacher has the opportunity to hear exactly how their referral is being handled differently, in a one-on-one setting, they often come away with an understanding that the restorative approach provides a more meaningful outcome. Maggie would reinforce the benefits of these individual conversations: "I know that a lot of teachers probably don't come down, but for those that do, they get it. They understand that this approach is better, but they need to make the time." "I really want to be able to close the loop with teachers, they're taking the time to write the referral, I should be able to follow-up," Richard would reiterate.

Making time for communication with staff is essential. Unlike my original approach to discipline, that which focused on being expedient and not thoughtful, proper communication with staff takes significantly more time, and is vital to the success of any restorative approach. I often quipped with those teachers I met with that their investment of time and energy now, would 
pay significant dividends down the road. Finding the time for communication was a struggle, as

Daley would further discuss:

There's never enough time to talk with a teacher before or after a referral. There's just not. And so it seems like I'm not connecting back to [the teacher], but what I want to share takes time, and neither of us really have it.

One challenge Maggie is faced with in her desire to follow-up and communicate with teacher's is simply being exhausted by the daily work:

Every day, we see so many different kids in so many different situations, from freshman to senior. We watch kids struggle, and all along, we're trying to creatively find these restorative ideas that work to help them. It's draining sometimes; it's tiring too, trying to always meet everyone's needs.

These obstacles were reminiscent of my earliest years in the discipline office. Rarely did I give consideration to the individual needs of a student, or what the long-term effects of punitive discipline practices may be. When student behavior was brought to my attention, I felt as though it was my job to punish, and when that punishment didn't work, I punished again, only longer and harder. Now that's exhausting.

\section{Theme II: Training and Support}

It is a common misunderstanding that restorative discipline is merely a tool or technique applied to a behavioral event by someone of authority within the school setting. By contrast, the restorative model seeks to engage a series of integral members within the school community to support overall efforts. Although these efforts are usually orchestrated from one individual or position, the model seeks to involve an array of active and interested members from the staff and community. This team of individuals generally includes a school administrator, teachers, guidance counselors and/or a social worker, as well as parents and community members. 
The implementation process at Northwestern High School has proved challenging for the deans, primarily because they lack any clear support structure. "Sometimes I feel like it's only us. Really, outside of a few others in Student Services, it's just us," Daley would say with a relatively weary expression. "The people who are going to step-up and do something with [restorative discipline], already have." Restorative practices are designed to be an encompassing mindset of all school personnel, however, early efforts to include these supports were met with reluctance. "Not everyone wanted to jump in, and I understand that, who wants to add more to their plate," Richard mentions. Maggie would add: "Some of the people I talked to about this early on just said 'okay, let me know what you need me to do,' but I can read into this. I could tell who was interested, and who wasn't." During one of our first group interviews, both Richard and Daley would talk at length about the lack of support they feel in the implementation process. While both acknowledge that their colleagues are generally willing to come forward and serve in a restorative conversations and process as needed, it is only after the dean's office has taken the lead in the matter, and directed the efforts.

One reason for this obstacle at Northwestern, and likely many other schools, is that issues of discipline are traditionally handled by individual(s) assigned to be specific role within the school. At Northwestern, this equates to three student deans being largely responsible for the disciplinary events of over three-thousand students. This includes all attendance, truancy, and chronic absenteeism, as well as the general day-to-day behavioral events.

I recognize this frustration having also served as a disciplinarian in a school that was slow to move beyond traditional practice; notwithstanding the full-staff presentations and departmental meetings regarding the restorative philosophy. However, one exchange in particular continues to remind me of the silver lining found behind some of the reluctance staff 
members will have: During a departmental meeting with physical education teachers, we discussed, at length, how to restoratively address the ongoing issue of class truancy, students not dressing for class, and failing grades. Much of this approach centered upon improving communication with students, and their parents as needed. This individualized the conversation, allowing teachers to learn more about exactly 'why' a specific student refused to dress and participate. Several weeks later, one of these teachers stopped by my office and stated simply, “kids don't participate because they don't like the class...I can't change that, so I'm writing referrals." While frustrating to hear in the moment, data towards the end of the semester would reveal a decrease in 'PE non-dress' referrals overall, as well as slight improvements in daily attendance and the percentage of students with passing grades. Armed with this knowledge (and a box of doughnuts) I invited myself back to a departmental meeting one morning to quickly share how their efforts were making a difference. Moments like this help build support for the restorative philosophy, especially when teachers are recognized for their commitment and effort.

However, because there was little done to formally introduce restorative practices to staff at Northwestern, support systems have been slow to establish, and interest has been limited. Not long after the need for additional staff was evident, the deans 'recruited' assistance from the school psychologists. "So much of our discipline is tied to a student's mental state, the psych's seemed like an easy choice. Besides, we already use them a lot anyway," Maggie states. The relationship being referred to, between the dean and a school psychologist, already exists in the discipline office, but not necessarily in a restorative manner. It is common practice at Northwestern High School to have a school psychologist present during any formal interview or questioning of a student with an active IEP. When exactly this procedure was put into effect, is unknown, but the practice exists. "Whenever we've got a student situation with an IEP, where I 
need to question them, we have a psych present. I guess it's to protect the student, and maybe even me," Maggie acknowledges. The restorative model is a natural fit, adds Daley: "Most of the referrals we get are written for kids with IEP's, so they're already seeing one of our psych's. So I might organize the response, but now they get in the conversation too... and not just sitting there." Richard was a bit more reluctant to applaud these connections to the school psychologist, or other primary support staff (nurse, social worker, case manager, or counselor) because he still finds that being the dean means he needs to take the lead and organize the bulk of the efforts, and that nothing seems to be natural, or organic.

This is a team approach, right? I don't take the lead in mental health issues or a physical health issue, but we're always there to support... part of the team. But we take the lead on everything, it shouldn't be that way.

Throughout the research, references are often made to specific staff members that are either helpful, and on-board with restorative practices, and thus a pleasure to work with, or those that simply stand to get in the way. "I know what direction to take with discipline based on who wrote the referral," Daley would share openly. Which means that the application of restorative practices is not necessarily being applied evenly. When asked about this, Daley admitted:

I know which people will actually care, and who will understand the students' needs. It's not everyone, so I don't even bother with some and help the kid out the best I can...it's better without certain people, you know, it's just easier.

The deans will agree that involving some staff members in their response, or inviting them to participate in restorative conferences, is extremely frustrating because they often take such a negative tone. For Daley, the issue of support extends beyond the immediate staff to include other key stakeholders in the restorative process, like the Board of Education.

The background for Daley's frustration comes from a discipline incident earlier in the year in-which communication came down from the Board of Education essentially questioning 
why a particular event hadn't resulted in an expulsion hearing. The student involved was found to be selling drugs in school, and was caught on multiple occasions. While past practices would have likely moved towards immediate expulsion, Daley was working closely with other staff members to find the right levels of support for this student, thus providing for a safe and healthy return to the school setting. He felt compromised when communication trickled down to him that school board members were questioning this approach. Daley would share: "This kid has a history of drug and alcohol abuse, issues with gender identity, and is estranged from his biological mother. The school board doesn't know these things, but they want me to put together an expulsion packet?" "So is the school board supporting us or not," Daley would ultimately ask. While school districts have an obvious need for discipline policies to exist in order to ensure the safety and wellbeing of every member of the learning environment, the actual discipline practices themselves are rarely given much attention beyond the scope of those most directly involved. This is where training and development plays an important role in successful implementation.

The deans have each attended Restorative Discipline training sessions offered locally through the Illinois State Deans Association (ISDA). The ISDA is a statewide organization comprised of high school principals, assistant principals, deans and assistant deans who deal with student discipline, attendance, school safety, security and other similar concerns. Throughout the year, the ISDA provides a variety of professional development conferences, often led by local school leaders that have specific training and/or experience. Restorative Justice in the school setting has been a popular, and often repeated topic of interest, with multiple presentations offered. Maggie and Daley also attended a conference on Senate Bill 100, which, in addition to updates on the legal requirements of school discipline in the state of Illinois, also included 
breakout sessions on alternative practices. "I think there's always some 'takeaway' from getting out of the school and talking with other people," Daley would remark. I've personally had the opportunity to not only attend, but also present on my experience with implementing restorative practices both locally and nationally. It was exciting to have Judy Mullet, co-author of The Little Book of Restorative Discipline for Schools, attended one of my sessions at the national ASCD Leadership Conference in 2015. She introduced herself to me afterwards, complementing the journey and development of restorative efforts, and referred to me as a 'kindred soul.'

Throughout these, and other conversations, I've learned that restorative implementation is difficult to piecemeal together, and that stopping along the way to reflect on what's being done, and making improvements, is absolutely necessary. As a group, the deans along with myself, have recognized that training for staff needs to be improved, and that without more effort in this area, we risk actually making discipline situations worse. Maggie reiterates this point as well: "We need more time with this, I think it's going to be a constant cycle of training and retraining people. Right now, the only real training occurs when [the teacher] comes to us."

By providing more training opportunities for staff, the deans also hope to improve upon their own practice, by learning from others. "When it's only us, we sometimes run out of ideas," shares Maggie. There is an admitted lack of creative problem solving from the deans, and in some instances, this lack of creativity results in quick resolutions designed to simply control student behavior and appease the teacher. "Sometimes I just need the behavior controlled. I want it controlled right now, and then move on," Maggie would admit. "There's nothing more frustrating than feeling like I'm just at a loss, or that I don't know what else to do anymore," Richard expresses. Although we would often talk about how the restorative process is not the denial of consequences, but rather the helping of students to better understand the impact of their 
behavior, and to commit to positive changes - the deans felt as though each student still needed a specifically named restorative measure applied to their behavior. I came to the realization that, while their mindset was still restorative in nature, the deans still needed to have a defined outcome. Traditional practices work that way; a student behavior is clearly identified, and some consequence among a vast array of options was attached to said behavior - as a 'consequence', and one that the referring teacher could see as well. Maggie: "When we close a referral in IC (Infinite Campus), we're using 'other' or 'conference with an administrator' because all the other options are punitive." These conversations led to my understanding of 'idea fatigue' - the notion that coming up with fresh and innovative ideas that were restorative in nature was exhausting, and that by adding more people into the restorative mix, the deans could reinvigorate meaningful responses.

\section{Theme III: Developing Relationships}

Nelson, Lott and Glenn share that, "Research has shown that the greatest predictor of academic success is the students' perception of 'Does the teacher like me?"' (p. 25). The restorative discipline model seeks to make individuals feel cared for and important. Common comparison between traditional school discipline and the restorative model are likened to a bank account. If you take money out, without ever making deposits, you will go bankrupt. By contrast, if you make periodic investments that exceed your withdrawals, your money will grow. Educators often refer to a 5:1 ratio (deposits: withdrawals) in order for students to feel good about their place in the school setting and to achieve academically. Whenever a student is confronted for a discipline referral, a withdrawal is made. Which echoes the proverbial hallmark to the restorative discipline model, an approach that, when implemented properly, improves relationships. 
Building a trusting relationship with students and staff was a primary focus throughout the restorative implementation process. With each interaction, the deans sought to develop understanding and help support good student character. "It's not a consequences approach anymore. It's about the relationship, not the rule breaking," Daley would quip. While past practices were never intentionally discourteous, they were mechanical and somewhat abrupt, only being mindful of control and the administration of punishment. The office staff followed suit, by processing referrals as dispirited kids stood by, awaiting their detention reminder and pass back to class. By simply making students feel valued, listened to, and important, the entire discipline office environment changed significantly. One of the more uniquely unintended consequences, is that the discipline office became somewhat of a 'hangout' for students. As one girl mentioned "it's a place to come and get away from the nonsense, you know, avoid drama." One of the administrative assistants would also share: "It's taken some getting used to actually. He used to be a lot quicker, and kids would be in-and-out, now they're hanging around longer, wanting to talk. And that never used to happen."

Being proactive in managing students' behavior was also a priority of the deans when implementing restorative practices. It was common for conversations with one student, to quickly lead to a conversation with another, and yet another, until there would be often be a quick group intervention or conference in order to get ahead of a potential issue. One example, while walking through a hallway, I noticed Richard quickly ushering two girls out of a crowd and into a nearby conference room. As I walked in behind them, I overheard Richard; "We've talked about this...you both know how to avoid this... so, what do we need to do in order to make this right?" It wasn't long until there was some mutual accountability and an agreement to 
let the issue rest. "In the past, I probably would have focused more on who did what, trying to figure out who was more to blame, and then punish from there," Richard would comment.

Schools are notoriously retributive in this manner, focusing on the rule broken and where to assign the guilt - managing behavior through punishment, not conversations. The focus on moving a school from a retributive lens to a restorative leans means shifting from: (1) focusing on blame-fixing to problem solving; (2) focusing on the past to focusing on the future; (3) focusing on punishment to focusing on repairing harm; (4) neglecting victims' needs to victims' needs being central; (5) neglecting offenders to offenders being given a role; (6) neglecting victim-offender relationships to victim-offender relationships being central (Zehr, 1990).

In an effort to remind myself of this shift in perspective, I recreated the words into a small visual [see Appendix C] that I posted on my desktop and shared with the deans. "I need a reminder of what I'm doing from time to time, especially on days like today," Daley would share during a conversation in which I referenced this particular visual posted above the phone in his office. "Ya, I really don't put things like this up, but I figured you wanted me to. But actually...I do actually look at it sometimes," he would close with a laugh.

The restorative discipline paradigm, moving the school community away from the retributive lens to a restorative lens, has also had a significant impact on the relationships between adults. Although the natural emphasis of relationship building in the restorative model is student-centered, or between a student and a staff member, I was intrigued to also learn how relationships grew between the adults involved as well. 'It's always been an 'us versus them' mindset in this school," stated Daley. And, over the years, I've heard similar quips from teachers about "the administration," always feeling somewhat insulted by such comments as they imply some type of manipulation, coercion or control. However, as we'd also uncover, administration 
makes stereotypical remarks about teachers as well; the troublemaker who always has to question decision making, or the union rep that always seems to try and overexert their authority and influence. "I know there are teachers I react to differently, just because they rub me the wrong way," Richard admits. "But I try and have a level head, to make it about the kid." As a group, we would often talk about how their restorative approach with students must be sincere and respectful, but we never really discussed how this same demeanor must be present when talking with the adults involved as well. Richard: "Teachers don't get us in a lot of ways; they don't get what we're doing, I don't know if we should worry about it, do more...or what?" Prior to the implementation of restorative practices, the dean-staff relationship at Northwestern High School is best described nondescript. While there are some closer relationships based on personal familiarity, most interactions between the dean's office and staff were limited and very general. "It certainly wasn't a bad existence, we just did our thing, [the teachers] did theirs," Daley stated. The inclusion of staff members in the discipline referral process definitely changed this. One simple example is quite visual, actually seeing teachers coming and going from the discipline office, something that has become more commonplace, but was certainly not the norm for several years. This is an experience I recall from my time in a previous district as well, where the office dynamic would slowly change. Like that of Northwestern, the discipline office was a relatively isolated and stale environment, where even staff members were unsure of exactly how to manage procedures or where to go. "It always just seemed really intense, like I was interrupting or didn't really belong," said one teacher. The restorative approach creates a healthier atmosphere, and has helped the discipline office transition to one that has become much more open, inclusive and welcoming. The environment being created for students is having a naturally positive impact on the staff as well. Maggie shared an exchange she had with a teacher 
following a restorative conference: “She just said 'thanks,' you know...we've never seen eye-toeye on discipline, but there was something there, I could just tell. She ended up bringing another student down, we connect on this approach... she sees that too, I think." That's not to say that all relationships will be easy to manage. During my first year introducing the restorative philosophy, I was met with several challenging situations. On one occasion, I recall attempting to introduce a restorative conference as alternative to a lengthy suspension for a student that had threatened a teacher. My intent was for the student to connect with our school psychologist ahead of time in order to reflect and process his conduct in order to articulate this during a conference that would include his parents, a guidance counselor and the teacher. The student himself was very remorseful and was taking ownership of the harm created, additionally, agreeing to also seek continued counseling. This approach was communicated during a face-toface conversation I personally had with the teacher, during which she appeared to agree with this approach. I was disheartened to learn that a short time after leaving my office, she sought advice and protection from our teacher's union representative, stating that she still felt fearful and wanted the student removed from her classroom. And, during conversations that I was not directly involved with, the student was soon removed from the class roster.

Many teachers do not see conflict as a learning opportunity. While the restorative mindset supports the building of trust between students and adults, there sometimes needs to be a willingness to move outside one's own comfort zone. When this occurs, the positive relationship developed has a trickle affect as well. Once one person has a good experience with a restorative approach, they are likely to share this with a colleague that may be dealing with a similar problem. In many cases, I've had teachers reach out to me directly, asking if I can help with a classroom management approach or specific student issue, simply because they'd heard from 
someone else that I was interested in this, willing to help, and would make the time to do so. Daley also recognized how time became an important factor in developing relationships with teachers: "We have the benefit of time with the kids. [The teacher] is on an assembly line, almost 130 kids plus their curriculum. They're being pulled in a lot of different directions. I get it." By spending time with teachers, whether in the office with, or without a student, or by going into classrooms and modeling conversations, the restorative mindset and overriding philosophy continues to grow.

During our last group interview, Maggie shared her wish to “...just hit the reset button and start over." She continued, "I know we're in a better place with discipline, regardless of the frustration, but I would still like to have a few 'do-overs' with how things started off." Although irritations and exasperations far outweighed the ah-ha's and celebrations, there are visible signs of progress being made at Northwestern High School. In speaking with a fellow colleague about the research, I used an analogy to help explain how the data materialized: Think of a favorite photograph from a family vacation, and then narrow your focus to only one square inch - the exposed area alone cannot explain the entire event - it will only provide a fragment of something more wonderful. When analyzing the research, I needed to remind myself several times to actually back away, and take a look at the larger picture that was emerging from the data. And when I did, I liked what I saw. 


\section{CHAPTER V: RESEARCH SUMMARY AND CONCLUSION}

The purpose of this research study was to examine the work of three disciplinary deans and an associate principal, as they review current school practices, and examine the implementation of a restorative discipline model in a large suburban high school. Over the preceding chapters, a historical perspective of traditional school discipline practices and the negative impacts of an overreliance on zero-tolerance policies was reviewed. Utilizing an action research model, I examined the practicality and unique challenges of implementation, giving specific voice to the individuals most directly involved in the process.

This chapter discusses the findings and implications for education, then addresses the limitations of the research and presents recommendations. The interviews and field notes captured information related to the research questions that guided this study:

1. What is general feeling of our staff when considering the effectiveness of our current discipline practices and how they impact school culture?

2. What preconceived notions exist about the implementation of a restorative justice model at Northwestern High School?

3. What elements of concern or trepidation may exist in the development and implementation of a restorative justice model?

4. How might the implementation of a restorative justice model change student-student and student-teacher relationships at Northwestern High School?

5. In what other ways might the learning environment may be impacted by the implementation of a restorative justice model at Northwestern High School? 
Myself, and the participants met formally as a group, as well as individually throughout the research timeline. This included many impromptu observations that came about as the result of more complex disciplinary events - events that I would naturally be a part of regardless.

Many moments throughout the research also provided opportunities for me to observe participants interacting with students, teachers and parents. These field-notes were useful in sparking follow-up conversations and for helping me draw out the differences from dean to dean and event to event. Field notes were devoid of any descriptive detail, and more often held key words, phrases or questions that would spur my memory in follow-up conversations. At one point, I attempted to structure my note taking format in order to better organized my thoughts and make them more 'user-friendly' for later review. This never materialized, and most notes remained simply an array of random and sometimes incoherent fragments of information. Field notes did not help in capturing the more important emotions that emerged, nor did they help reconstruct any event in order to offer improved data. Sometimes I would compose field notes after events took place, but often lost some of the more important factors until a follow-up conversation would actually help jog my memory. In short, the use of field notes was most helpful in reminding me to ask follow-up conversations, or to recall a specific approach or statement that may have been useful in constructing data.

\section{Research Summary}

According to a 2012 report from the National Center for Educational Statistics (2012), of the 49 million students enrolled in public education, 3.45 million students will be suspended. This same data source also indicates that students with disabilities and students of color, are disproportionately impacted by such practices. Although these disparities in discipline remain significant, a Civil Rights Data Collection (2016) report from the 2013-14 school year revealed 
that, over a two-year span, suspensions nationwide decreased by nearly $20 \%$. Scrutiny over suspensions and the severely damaging effect these practices have upon youth has spurred school districts across the nation to begin rethinking their discipline approach and find alternatives (Amstutz \& Mullet, 2005; APA Zero Tolerance Task Force, 2008; Ashely \& Burke, 2009). The three participants of this research study, Richard, Maggie and Daley, all share the same perception - that traditional school discipline practices and adherence to zero-tolerance policies have a negative impact on the individuals involved and the school culture. These same participants, including myself, have begun to reshape discipline at Northwestern High School using a restorative discipline mindset, an understanding that behavioral events should become an opportunity to teach, not punish. The restorative framework has provided an intentional response to behavioral events that encourages accountability and emphasizes the need to make things right. At the onset of this research study, each participant, including myself, recognized his or her own biases, range of experience, and comfort-level in the implementation of a restorative discipline model, and each reacted differently when presented with the initial scope of the study. After Maggie learned of the research, and had an opportunity to digest some of the information presented, she began asking questions in order to better understand her role, "I like to think I'm in control of what decisions happen in my office. I need to answer to them...this feels like a team approach, which is fine, but where do I fit in?" In contrast, Richard shared more of a natural openness to the research, "Sounds worthwhile, I'm open to trying something new," while Daley was more reluctant, "How much time is this going to take?" Regardless of their starting point, each of the participants agreed that the discipline approach at Northwestern needed to change. "I know that some of things we currently do, don't make sense...they don't work for kids," said Daley. When I asked Daley to explain this in more detail, he mentioned his 
own frustrations in seeing a growing number of student continuing to spiral downwards in their behavior, attendance, and grades. Richard also noted that the number of students who were "skipping" their detentions or assigned consequence was on the rise, and that teachers were getting frustrated because nothing appeared to be getting done.

Though suspension continues to be a widely used disciplinary technique, this approach has raised questions related to even more undesirable outcomes related to less healthy schools, lower academic achievement, higher levels of disruption, increased anti-social behavior and higher school dropout rates (Skiba, Ritter \& Simmons, 2005). Richard would admit that putting a student into in-school-suspension became a routine course of action prior to being more restorative in his thinking because it contained the student in one location, and gave the appearance to teachers that an unruly student was being punished. "Sometimes I just went right to [in-school-suspension] because it was easier than chasing [students] around," Richard would admit. Undoubtedly, the need to control negative behavior is a significant pressure faced by school administrators, but how that control looks is beginning to change. School districts are now looking for more appropriate and meaningful alternatives that keep students in school, moving forward educationally, and behaviorally.

While restorative discipline serves as one of these alternatives, simply announcing that school discipline practices have become restorative doesn't make it so. The deans at Northwestern High School have developed a restorative mindset, and have supplemented their existing discipline 'toolbox' with practices that promote this ideal, but the actual shift to a school wide restorative model is still relatively basic. "We're just not there yet, and that's on us to fix," Maggie would assert. One contributing factor is that the staff at Northwestern was not formally introduced to restorative practices, which led the deans to feel like they were always needing to 
justify their actions. "The rollout needed to be more strategically planned," Richard would comment. Teachers felt frustrated when issuing a referral for misbehavior, only to have the student returning back to class shortly thereafter and feeling as though nothing more than a conversation has taken place. This only served to exacerbate a school culture that already seemed to carry a mild 'us versus them' mentality when it came to the teacher/administrator relationship. "There was a lot of misunderstanding at first...[teachers] were used to us keeping kids out of class, but now we're sending them back, preparing a conference, calling parents, notifying supports, finding alternative consequences, and trying to notifying the teacher," Maggie would say with a tone of sarcasm. Richard and Daley were quick to echo these sentiments, expressing that as the lead for every discipline referral, they naturally felt responsible to also coordinate every restorative response. Other staff members are willing to assist in restorative problem solving, however, there is ultimately a relative shortage of human resources available when it comes to the time required for actually initiating a meaningful response in a timely manner. I observed many restorative conferences throughout the research timeline that fell heavily upon the shoulders of the deans from start to finish. In addition to not only leading the restorative conversation, the deans would also be responsible for coordinating the schedules of all individuals involved in order to explain the crux of this approach - which was new to almost all.

In order to try and dispel teacher confusion on the restorative efforts taking place, the deans focused their communication on departmental meetings. The goal was twofold. First, to send a broad message regarding the critical role staff members have in shifting their classroom management language to be more reflective of the restorative philosophy. Secondly, to recruit some interested volunteers that may want to become part of the restorative discipline procedures 
taking place. "The right people seemed to hear the message... some just don't get it, and they're not going to get it. Thinking restorative (sic) can be hard for people," Maggie quips. Overall, the deans made progress in communicating the restorative efforts to the staff, department by department. And, had some success in creating a list of staff members that would be willing to give of their time to learn more about the restorative discipline procedures taking place and how they might support these efforts. Having additional people involved in the restorative process is something the deans were really excited about, having recognized that their own lack of creativity likely generated moments of missed opportunity for students, often finding themselves in situations in which the need for control and quick resolution took precedence over a more appropriate response. As Daley admits, “there were just times it didn't work for me...I went back to old ways." This has caused inconsistencies in their practice from one student to the next, especially with the perceived need to balance student well-being with teacher satisfaction in discipline procedures. "It's important that I support the teacher, but more important that I support the kids, I get it. But sometimes that's a balancing act," Richard comments. The deans also found themselves completely exasperated with the amount of time, effort and energy, restorative approaches would sometimes take. Richard, after one particular day, would state with exhaustion:

I dealt with the same kid all day, and I'll never really know if I made a [difference]. You hope that something is happening with all of these conversations, but at the end of the day, is this really working?

Despite the exhaustion, shortcomings and frustrations, there is a silver lining to the work being done at Northwestern High School. More and more staff have begun to comment on their own classroom success stories, and some have mentioned how their management strategies will now include a more restorative approach. Looking forward, the deans have plans to further develop 
the leadership capacity of others, and to create a more efficient management system for organizing the restorative responses. Maggie is also planning to visit a neighboring school in order to learn more about their peer jury and peer mediation programs. "There's an opportunity here, to learn from a school that already has some restorative programs up and running," she would share. In the final chapter of their book The Little Book of Restorative Discipline for Schools, authors Lorraine Stutzman Amstutz and Judy H. Mullet (2005) share:

A place to begin may be to assess what restorative components are already being used. "Start with what you do and do it better" should be the mantra. Start with the belief that when we celebrate what's right, we will have the energy, creativity, and inspiration to work at changing what is wrong. (p. 79)

This is roughly where the deans at Northwestern High School would acknowledge they currently exist - continuing to identify what they do well, and thinking about ways to do it even better.

\section{Findings}

The participants of this research study, all administrators of a large suburban high school, share in the belief that traditional discipline measures are not effective, and have a severely negative impact on individual students, and the school culture. Current practices at Northwestern High School provided little opportunity for offenders to learn and take responsibility for their action, instead, punishments are designed to create a negative experience with the hope that this feeling would deter future behavior. Instead, students ignored the consequences, blamed others, and often spiraled further into habits of poor decision making and despair. In-school and out-of-school suspension consequences were especially damaging as students that were already struggling academically only fell further behind, and were often too embarrassed or frustrated to go back to classes, initiating referrals for truancy - and the downward spiral began again. The discipline office at Northwestern High School was factory- 
like in its approach to churning kids in and out. Maggie, in particular, recognized that this domino effect needed to stop, and that their office actually seemed to be perpetuating some of the animosity and ill-will students directed toward the learning environment. "Nobody wants to be called to the discipline office, it usually means you're getting in trouble. And kids usually were, so they left angry and frustrated." This feeling was evident by the tone students projected upon entering the office, and even more so upon leaving. 'I'd say that most kids didn't even listen to what I was saying, they were just like 'okay, what's my punishment," Richard would add. It was not uncommon for students coming to the discipline office to behave disrespectfully to staff members as well. Each participant recognized that their discipline office environment was toxic to student morale and needed to change.

As comfort and familiarity with restorative practices increased, conversations emerged that would ultimately lead to the redesign of school discipline practices at Northwestern High School began. There was a range of emotions from the onset, worrisome (Maggie) and guarded (Daley), to wildly optimistic (Richard). Regardless, each participant saw that improving discipline practices had the potential to impact the greater good of the school. Among the first steps taken by the dean's office was to begin using restorative language, adjusting from an approach that sought to find guilt and apply punishments, to finding an understanding, and helping students to take responsibility and make things better. All of the participants identified moments when having used a developed restorative language created a much more enjoyable student discipline experiences. Maggie was the first to point out that changing her language immediately changed the student language, and that soon a peaceful, more meaningful resolution could be found. At the same time, each of the participants found restorative conversations to be more time-consuming, and while beneficial to a larger degree, the volume of students to be seen 
was overwhelming. Organizing conferences that involved multiple participants such as parents and community members, as well as peer mediations and other restorative discussions was a significant commitment of time that was difficult to manage for the deans. Each participant voiced the need for more trained staff members that would be available to take the lead in these efforts. This lack of time and additional support was also shared as the reason why each dean would also admit to sometimes not using a restorative approach when such an effort would have been possible. The participants each shared disciplinary moments when the feeling of being overwhelmed caused them to revert back to quicker decisions and more easily managed actions. Maggie believed that by having additional staff members to work alongside in the development of restorative programming, there would be more creativity to their approaches as well. For the most part, the deans found that the communication with staff during departmental meetings was helpful for sharing the basic restorative approach teachers should expect from a referral. Maggie and Richard believe the staff members were receptive to the restorative mindset, albeit with many 'what if' questions that couldn't always be answered in-depth given time constraints. Daley found the departmental meeting less helpful, believing rather that most staff are not open to restorative thinking, and that most will not change their referral writing habits and hopes for a traditional consequence to be applied. Richard, Maggie and Daley are all looking forward to additional training opportunities in the fall, specifically in the development of a peer jury program and how to manage peace circles. They are also hopeful that other staff members will be able to join them.

The participants identified the restorative approach as having a profound impact on the office environment. Maggie would identify that students had become more actively engaged in conversations and proactive in their personal efforts to address feelings and behaviors to avoid 
discipline events before they occurred. I also noticed that the office environment had transitioned from one of relative gloom, to something more up-beat. Students did not seem to be coming and going with such a sense of despondency as they had in the past. One of the simpler changes that I came to appreciate was the dean's conversion of their in-school-suspension room to a processing room. This included changing the physical layout from desks being in rows, to a circle, thus creating an environment where students could 'drop-in.' On one particular visit, I was impressed to see that students had organized their own peace-circle, of sorts, and although not by definition, these individuals were looking to solve a situation on their own. Having been afforded this space, and knowing that these types of conversations were valued, made this possible.

\section{Implications and Recommendations for Practice}

Implications and recommendations for practice are based on the data collected throughout this research study. This includes observations and interactions with the research participants, as well as drawing from my own personal experiences. This information allows me to formulate opinions and make several recommendations for improving the implementation of a restorative discipline model in a school setting. These recommendations will be useful to school administrators and teachers being called upon to examine disciplinary policies, and consider their alternatives. Restorative discipline helps to empower students and staff to resolve behavioral events through more meaningful dialogue - serving to teach instead of punish, and to keep students in school rather than to suspend. The deans at Northwestern High School have adopted this restorative mindset, and are looking to build upon their skills in order to have an even greater influence on the building culture for years to come. 
In order for a restorative discipline program to become a truly culture-changing phenomenon in the school setting, every single staff member must be aware of, and trained, in this mindset. While relying on "experts" to deliver training and ongoing professional development, I have found that some of the best deliveries of the restorative discipline mindset are grassroots in nature - real-life stories that are relatable from a familiar voice. Whenever I've shared my own personal experiences, which have always included my mistakes and stumbling along the way, the response has always been more receptive to a further understanding of the restorative philosophy. In addition, the language restorative discipline requires needs to be heard and modeled. I also don't believe that it is necessary for these presentations to be formalized and delivered to a large audience. Restorative discipline is a relatively intimate and personal process; the delivery model should be as well. There is a human-touch element to these presentations that can be too easily lost in the larger settings. The deans and I have found the most successful communication platform is from departmental presentations. These experiences, for the most part, have evoked the richest conversations and created the deeper levels of understanding we were hoping for. As presenters, we also customized our messaging in order to more specifically target the unique needs of each group. This sort of individualized attention within a smaller setting naturally provided more opportunities for people to ask questions and seek further understanding.

Beyond providing a general overview to the staff regarding new restorative procedures, key staff members must also receive formal training on the core components central to the restorative mindset. While not serving as a day-to-day dean of student discipline at Northwestern High School, my administrative role is central to identifying the broader needs of the school environment, ultimately looking to improve upon them. To say that the redesign and 
implementation process of a new discipline approach has not been personal to me would be a vast understatement. I may argue that the pains and frustrations of the deans, to a large degree, became my own burdens to bear - often feeling personally responsible for their emotional strife, thus always seeking opportunities to adjust, tweak, and better support their daily work "in the trenches." Having multiple staff members trained in the language and practice of restorative discipline is important to supporting the delivery mindset. As more and more disciplinary events uncover the greater need to support a students' social emotional well-being, I recommend that specific restorative training sessions take place for psychologists, social workers and counselors. This includes training in targeted approaches that a school may be interested in pursuing. Northwestern High School, for example, has developed an interest in creating a peer jury program, and learning more about running successful peace circles. Both programs offer training, and have been implemented in other high school settings in our area, creating a unique learning opportunity to acquire new knowledge through observation and the direct experience of others. And with this continued professional development also comes a new opportunity to restructure the discipline workflow.

I have observed throughout this research study many ways in which a traditional discipline office could be transformed into something far more powerful than imagined. In addition to the restorative mindset, I believe there also exists great need to improve procedural workflow. For example, I have observed how the discipline office naturally becomes factorylike in the need to constantly keep pace with referrals. As a frame of reference, during the 201516 school year, there were 8,897 referral events entered into the Infinite Campus Student Management System at Northwestern High School. If we were to take this number in rawest form, each dean would see nearly 3,000 students per year, roughly 16 students each day from the 
first to last day of school. However, $89 \%$ of these referrals $(7,906)$ were related to attendance issues; tardiness and truancy - most of which are handled through an automated mass detention system that creates electronic reminders for before-school, after school, or lunch detentions. Another 7\% (609) can be categorized as 'non-aggressive' behaviors, this includes referral events like parking violations, misuse of a pass, or overdue library fines. Here again, these referral events are generally addressed quickly, with little to no thought, and include simple detentions. The remaining 4\% (382) are considered to be more aggressive, or dangerous, in their nature; fighting, vandalism, theft, drug/alcohol possession, and harassment. These issues are more befitting of the time, effort and energy of a restorative response as they may traditionally have been met with exclusionary consequences. In order to serve students more restoratively, yet also efficiently, students with attendance and non-aggressive type behaviors do not need to be prioritized first, which sometimes became the case given the sheer volume of students that needed to be seen. By developing a restorative language for teachers, I believe that attendance related referrals, and other minor issues, can virtually become non-existent, with the more chronic attendance concerns falling into unique programs like Lunch \& Learn, developed this year at Northwestern, a program in-which top attendance offenders in the school would be periodically invited to a pizza luncheon that also included a presentation from local business leaders that shared their own motivational messages on the importance of developing strong work habits for college, work, and beyond. Feedback from students was remarkably positive, and for many, attendance did indeed improve simply because, as one student put it, "you did something different, something that actually made me think and feel differently." The remaining referrals, those related to more aggressive types of behaviors, can then become the sole mission of a well-developed, trained, and prepared core group of administrators, teachers and student 
services staff. These individuals can then be divided to share and organize restorative programming, simultaneously. For example, while one staff member is hosting a Peace-Circle for one group, another can be sharing a student/teacher restorative conference, with yet another supervising a Peer Jury. With cross-trained professionals, the responsibilities are such that any one person can serve in multiple capacities as needed and scheduled throughout the day. With school budgets, always being a concern, Northwestern is looking to implement such strategies beginning in the fall, by using teachers that have volunteered to serve in this capacity versus their contractual supervision, or extra-duty.

In his book The Little Book of Restorative Justice, author Howard Zehr (2002) notes that our traditional understanding of how to handle wrongdoing often revolves around three questions: What rule was broken? Who did it? And, what do they deserve? The restorative shift takes these questions and, rather than focusing solely on the rule-breaking and punishment, includes what harm has been done, and how to fix it: What happened? What harm resulted? And, what needs to be done to make it right? The contrasting questions are important to understand and use as part of the restorative language. I offer an additional question for consideration, one that I've used personally with many students: How can you help to educate others? I've come to realize that there is power behind having a student also feel empowered enough to take ownership and educate their peers. When the tone and language of a discipline office is created by adults, it feels like it has been created by adults. But when the tone and language of an "intervention" office is created by students; it is also more likely to better resonate with students.

Undoubtedly, the vast majority of schools looking to implement a restorative discipline model presently have an existing model that relies heavily on an entrenched system of 
punishments and consequences. Those consequences were designed to stop unwanted behavior through the hopes that some unpleasant punishment will deter future wrongdoing, and now it's not working. I've been involved in the basic assessment of these practices, reviewing suspension data, recognizing the alarming disproportionalities, and the negative impacts exclusionary measures have on specific sub-groups. It pains me to also share that I've been in these same meetings where little was done as result. It is however necessary to take these critical steps, steps necessary to determine where you presently are - and where you want to be. The flawed logic behind punitive punishments has been well documented throughout this dissertation, yet continues to be the dominant response in schools simply because punishments are easy to apply and give a sense that "something was done." Restorative discipline helps schools move beyond punishment by applying an appropriate action that encourages accountability and the reparation of harm, giving us a new thought that "something was learned."

\section{Closing}

In her work, Caring: A Feminine Approach to Ethics and Moral Education, Nel Noddings (1984) states, "the aim of education is to reveal an attainable image of self that is lovelier than that manifested in his or her personal acts" (p. 193). I believe this line of thinking allows us to recognize that situations of wrongdoing in schools, which require some form of disciplinary action, can in fact, be opportunities for growth. When viewed in this manner, school leaders move beyond viewing discipline as an opportunity to punish, but as an opportunity to learn. This evolution is reflective of a restorative mindset, one which should be used now, by all schools in response to the growing dissatisfaction with traditional approaches that are not only found to be ineffective, but also damaging to the development and well-being of youth. While the philosophical approach behind restorative practices requires a shift in both mindset and skill 
set, the results of repairing a student's relationship with the environment and the people around them, has proven well worth the effort. Restorative programs have been found to be a successful intervention in response to some of the most common school related discipline issues, as well as being far more meaningful for those behavioral events that are increasingly complex. With an almost limitless combination of possibilities for implementation, the restorative model offers a promising alternative that is healthier, and more indicative of the nurturing environment schools are meant to be - for within their walls is the ability to truly form and develop a kinder human response. It is therefore, indeed possible to teach tolerance, accountability, respect and understanding. And the restorative discipline model accomplishes this. 


\section{REFERENCES}

Advancement Project. (2010). Test, punish, and push out: How zero tolerance and high stakes testing funnel youth into the school to prison pipeline. Washington, DC.

Advancement Project. (2005). Education on lockdown: The school to jailhouse track. Washington, DC.

Ahmed, E., \& Braithwaite, J. (2005). Forgiveness, shaming, shame and bullying. Australian and New Zealand Journal of Criminology. Australian Academic Press, 38(3), 298-323.

Ahmed, E., Harris, N., Braithwaite, J., \& Braithwaite, V. (2001). Shame management through regeneration, Melbourne, Australia: Cambridge University Press.

American Civil Liberties Union. (2012). Hearing on: Ending the school to prison pipeline. Washington, DC: ACLU Legislative Office.

American Psychology Association Zero Tolerance Task Force. (2008). Are zero tolerance policies effective in the schools?: An evidentiary review and recommendations. The American Psychologist, 63(9), 852-862.

Amstutz, L., \& Mullet, J. (2005). The little book of restorative discipline for schools. Intercourse, PA: Good Books.

Angrosino, M. (2007). Doing ethnographic and observational research. Thousand Oaks, CA: Sage.

Armour, M. (2014). Ed White middle school restorative discipline evaluation: Implementation and impact, 2013/2014. The Institute for Restorative Justice and Dialogue. The University of Texas at Austin.

Arnott, K. (2007). Restorative justice: Making brand new endings. Education Today, 19(2), 2223. 
Ashley, J., \& Burke K. (2009). Implementing restorative justice: a guide for schools. Illinois Criminal Justice Information Authority.

Ashworth, J., Bockern, S. V., Ailts, J., Donnelly, J., Erickson, K., \& Woltermann, J. (2008). An alternative to school detention. Reclaiming Children and Youth, 17(3), 22-26.

Bazemore, G., \& Schiff, M. (2010). No time to talk: A cautiously optimistic tale of restorative justice and related approaches to school discipline. Issues in Criminological Theory and Research: The Role of Social Institutions. United States: Cengage.

Bazemore, G., \& Schiff, M. (2009). Addressing the school-to-jail pipeline: Restorative justice and theory for practice in real alternatives to zero tolerance. Paper presented at the annual meeting of the ASC Annual Meeting, Philadelphia Marriott Downtown, Philadelphia, PA.

Biehl, S. (2011). School expulsion: A life sentence. Section of Litigation: Children's Rights Litigation. American Bar Association. Retrieved online: https://apps.americanbar.org/litigation/committes/childrights/content/article

Bloom, B., \& Crabtree, B. F. (2006). The qualitative research interview. Medical Education, 40(4), 314-321.

Boccanfuso, C., \& Kuhlfeld, M. (2011). Multiple responses, promising results: Evidence-based, nonpunitive alternatives to zero tolerance. Child Trends. Washington, DC: Office of Juvenile Justice and Delinquency Prevention, Publication \#2011-09.

Bouffard, J. A., \& Bergseth, K. J. (2008). The impact of re-entry services on juvenile offenders' recidivism. Youth Violence and Juvenile Justice, 6(3), 295-318.

Bowditch, C. (1993). Getting rid of troublemakers: High school disciplinary procedures and the production of high school dropouts. Social Problems, 40, 493-507. 
Boyington, B. (2017, May 17). Map: Graduation rates by state. U.S. News and World Report. Retrieved online from: https://www.usnews.com/high-schools/best-highschools/articles/2017-05-17/map-see-high-school-graduation-rates-by-state

Brackett, M. A., Reyes, M. R., Rivers, S. E., Elbertson, N. A., \& Salovey, P. (2012). Assessing teachers' beliefs about social and emotional learning. Journal of Psychoeducational Assessment, 30(3), 219-236.

Brady, K., Balmer, S., \& Phenix, D. (2007). School-police partnership effectiveness in urban schools: An analysis of New York City's Impact Schools Initiative. Education and Urban Society, 39(4), 455-478.

Braithwaite, J. (1989). Crime, shame, and reintegration. Cambridge: Cambridge University Press.

Brown, L., Snyder, H., Hurst, H., \& Berry, S. (2010). A transition update: Peoria County balanced and restorative justice. Pittsburgh, PA: National Center for Juvenile Justice. Burke, K. (2013). An inventory and examination of restorative justice practices for youth in Illinois. Illinois Criminal Justice Information Authority.

Calhoun, A. (2000). A Calgary community conferencing school component 1999-2000: A year in review. Retrieved online from: http:// www.calgarycommunityconferenceing.com Calhoun, E. F. (1994). How to use action research in the self-renewing school. Alexandria, VA: Association for Supervision and Curriculum Development.

Cameron, L., \& Thorsborne, M. (1999). Restorative justice and school discipline: Mutually exclusive? A practitioner's view of the impact of community conferencing in Queensland schools. Australian Institute Conference. 
Casella, R. (2003). Punishing dangerousness through preventive detention: Illustrating the institutional link between school and prison. In J. Wald, \& D. J. Lose (Eds.), New directions for youth development: Deconstructing the school-to-prison pipeline (pp 5570). San Francisco, CA: Jossey-Bass

Cerrone, K. M. (1999). The gun free schools act of 1994: Zero tolerance takes aim at procedural due process. 20 Pace L. Rev. 131.

Children's Defense Fund. (1975). School suspensions: Are they helping children? Cambridge, MA: Washington Research Project.

Coalition of Juvenile Justice. (2010). Abandoned in the back row: New lessons in education and delinquency prevention. Annual report, United States Department of Justice.

Corey, S. M. (1953). Action research to improve school practices. New York, NY: Bureau of Teachers College, Columbia University.

Costenbader, V., \& Markson, S. (1998). School suspension: A study with secondary school students. Journal of School Psychology, 36, 59-82.

Creswell, J. W. (2007). Qualitative inquiry and research design: Choosing among five traditions ( $2^{\text {nd }}$ ed.). Thousand Oaks, CA: Sage Publications.

Curwin, R. \& Mendler, A. (1999, October). Zero tolerance for zero tolerance. Phi Delta Kappan, $119-120$.

DeVoe, J. F., Peter, K., Kaufman, P., Miller, A., Noonan, M., Snyder, T. D., \& Baum, K. (2004) Indicators of school crime and safety: 2004. U.S. Departments of Education and Justice, NCES 2005-002/NCJ 205290. Washington DC: US Government Printing Office. 
Dinkes, R., Kemp, J., Baum, K., \& Snyder, T. (2009). Indicators of school crime and safety: 2009. U.S. Department of Education, U.S. Department of Justice Office of Justice Programs, Washington, DC.

Dold, C. J., \& Chapman, R. A. (2012, May 20). Hearing a voice: Results of a participatory action research study. Journal of Child, Family and Student, 21(3), 512-519.

Eagle, H. (2001, November). Restorative justice in native cultures. State of Justice 3. A periodic publication of Friends Committee on Restorative Justice.

Fein, R. A. (2002, May). Threat assessment in schools: a guide to managing threatening situations and to creating safe school climates.

Ferguson, A. A. (2001). Bad boys: Public schools and the making of black masculinity. Ann Arbor: University of Michigan Press.

Ferrance, E. (2000). Themes in education: Action research. Brown University: Educational Alliance, 1-31.

Gale Database. (2001). The 1930s: Education: Overview. American Decades. Edited by Judith S. Baughman. Accessed September 182017 from: galegroup.com/apps/doc/CX3468301121/UHIC?u=sand55832\&xid=0354fefc.

Gewertz, C. (2017, May 3). Is the high school graduation rate inflated? No, study says. Education Week.

Gilmore, T., Krantz, J., \& Ramirez, R. (1986) Action based modes of inquiry and the hostresearcher relationship. Consultation, 5(3), 160-176.

Goldstein, A. (2006, October). Restorative practices in Israel: The state of the field. Paper presented at the Eighth International Conference on Conferencing, Circles and other Restorative Practices, Bethlehem, PA. 
Gregory, A., \& Cornell, D. (2009). “Tolerating” adolescent needs: moving beyond zero tolerance policies in high school. Theory into Practice, 48(2), 106-113. doi:

$10.1080 / 00405840902776327$

Gregory, A., \& Weinstein R. S. (2008). The discipline gap and African American defiance or cooperation in the high school classroom. Journal of School Psychology, 46, 455-475.

Guskey, T. R. (2000). Evaluating professional development. Thousand Oaks, CA: Corwin Press.

Hamilton, M. (2008). Restorative justice: Reconceptualizing school disciplinary theory and practice. Ed.D. Dissertation, University of the Pacific.

Hancock, D. R., \& Algozzine, R. (2006). Doing case study research: A practical guide for beginning researchers. New York, NY: Teachers College Press.

Heaviside, S., Rowand, C., Williams, C., \& Farris, E. (1998). Violence and discipline problems in U.S. public schools: 1996-97. NCES 98-030. U.S. Department of Education, National Center for Education Statistics.

Heitzeg, N. A. (2009). Education or incarceration: Zero tolerance policies and the school to prison pipeline. Forum on Public Policy.

Heitzeg, N. A. (2009, Winter). Race, class and legal risk in the United States: Youth of color and colluding systems of social control. Forum on Public Policy.

Herr, K., \& Anderson, G. (2005). The action research dissertation: A guide for students and faculty. Thousand Oaks, CA: SAGE Publications.

Hickman M. J., \& Reaves, B. A. (2006). Local police departments, 2003. Washington, DC: U.S. Department of Justice; Bureau of Justice Statistics. 
Hirschfield, P. (2008). Preparing for prison: The criminalization of school discipline in the USA. Theoretical Criminology, 12, 79-101.

Hirschfield, P. J., \& Celinska, K. (2011). Beyond fear: Sociological perspectives on the criminalization of school discipline. Sociology Compass, 5, 1-12.

Hollingsworth, S., \& Sockett, H. (1994). Positioning teacher research in educational reform: An introduction. Teacher Research and Educational Reform. Chicago, IL: The University of Chicago Press.

Johnstone, G., \& Van Ness, D. (2007). Handbook of restorative justice. Monsey, NY: Criminal Justice Press.

Johnstone, G. (2002). Restorative justice: Ideas, values and debates. Devon, IK: William Publishing.

Kaeser, S. C. (1979). Suspension in school discipline. Education and Urban Society, 11, 465484.

Kajs, L. T. (2006). Reforming the discipline management process in schools: An alternative approach to zero tolerance. Educational Research Quarterly, 5(4), 335-357.

Kang-Brown, J., Trone, J., Fratello, J., \& Daftary-Kapur, T. (2013, December). A generation later: What we've learned in schools. VERA Institute of Justice.

Karp, D. R., \& Breslin, B. (2001). Restorative justice in school communities. Youth and Society, 33(2), 249-272.

Kohn, A. (1996). Beyond discipline: From compliance to community. Alexandria, VA: ASCD. Kupchik, A. (2010). Homeroom security: School discipline in an age of fear. New York: NYU Press. 
Kupchik, A., \& Monahan, T. (2006). The new American school: Preparation for post-industrial discipline. British Journal of Sociology of Education, 27, 617-632.

Latimer, J., Dowden, C., \& Muise, D. (2001). The effectiveness of restorative justice practices: A meta-analysis. Ottawa: Research and Statistics Division.

Latimer, J., \& Kleinknecht, S. (2000).The effects of restorative justice programming: A review of the empirical research literature. Ottawa: Research and Statistics Division, Department of Justice Canada.

Lewis, S. (2009, May 19). Improving school climate: Findings from schools implementing restorative practices. International Institute for Restorative Practices. Retrieved online from: http://www.iirp.org/pdf/IIRP-Improving-School-Climates/pdf

Losen, D. J., \& Martinez, T. E. (2013). Out of school and off track: The overuse of suspensions in American middle and high schools: The Center for Civil Rights Remedies at The Civil Rights Project (UCLA).

Losen, D. J., \& Gillespie, T. (2012, August). Opportunities suspended: The disparate impact of disciplinary exclusion from school. The Civil Rights Project at UCLA.

Luke, G., \& Lind, B. (2002). Reducing juvenile crime: Conferencing versus court. Crime and Justice Bulletin, 69. NSW Bureau of Crime Statistics and Research. Retrieved on July 25, 2016 from: http://www.lawlink.nsw.gov.au/boscar

Lyons. W., \& Drew,J., (2006). Punishing schools: Fear and citizenship in American public education. Ann Arbor: University of Michigan.

Macready, T. (2009). Learning social responsibility in schools: A restorative practice. Educational Psychology in Practice, 25(3), 211-220. 
McCarthy, J. D., \& Hoge, D. R. (1987). The social construction of school punishment: Racial disadvantages out of universalistic process. Social Forces, 65, 1101-1120.

McCold, P., \& Wachtel, T. (2003, August). In pursuit of paradigm: A theory of restorative justice. Paper presented at the XIII World Congress of Criminology, Rio de Janeiro, Brazil.

McFadden, A. C., Marsh, G. E., Price, B. J., \& Hwang, Y. (1992). A study of race and gender bias in the punishment of school children. Education and Treatment of Children, 15, 140146.

McGarrell, E. F. (2001). Restorative Justice Conferences as an Early Response to Young Offenders. Washington, DC: U.S. Department of Justice, Office of Justice Programs, Office of Juvenile Justice and Delinquency Prevention.

McMillan, J. H., \& Schumacher, S. (2010). Research in education: Evidence-based inquiry $\left(7^{\text {th }}\right.$ ed.). New York, NY: Pearson.

Merriam, S. (1988). Case study research in education: A qualitative approach. San Francisco, CA: Jossey-Bass.

Merriam, S. (2009). Qualitative research: A guide to design and implementation. San Francisco, CA: Jossey-Bass.

Minnesota Department of Children, Family and Learning. (2002). A Three-Year Evaluation of Alternative Approaches to Suspensions and Expulsions. Report to the Legislature.

Mirsky, L. (2004, April \& May). Restorative justice practices of Native American, First Nation and other indigenous people of North America: Parts One and Two. Restorative Practices eForum. Retrieved from http://www.iirp.edu/article_detail.php?article_id=NDA1 
Mirsky, L. (2011, December). Restorative practice: Giving everyone a voice to create a safer, saner, school communities. The Prevention Researcher, 18.

Morrison, B. (2001). The school system: Developing its capacity in regulation of a civil society. In H. Strange, \& J. Braithwaite (Eds.), Restorative justice and civil society. Cambridge: Cambridge University Press.

Morrison, B., Blood P., \& Thorsborne, M. (2005). Practicing restorative justice in school communities: addressing the challenge of culture change. Public Organization Review: A Global Journal, Special Issue on restorative and community justice.

Morrison, G. M., \& Skiba, R. (2001). Predicting violence from school misbehavior: Contributions to suspension and expulsion. Promises and perils. Psychology in the Schools, 38(2), 173-184.

National Center for Educational Statistics. (2012). Status and trends in the education of racial and ethnic minorities. Retrieved online from: https://nces.ed.gov/pubs2010/2010015/tables/table_17b.asp

National Center for Educational Statistics. (2013). Trends in high school dropout and completion rates in the United States. Retrieved online from: https://nces.ed.gov/programs/dropout/index.asp

Nelson, J., Lott, L., \& Glenn, H. S. (2000). Positive discipline in the classroom: Developing mutual respect, cooperation, and responsibility in your classroom. Roseville, CA: Prima Pub.

Nelson L., \& Lind, D. (2015). The school to prison pipeline, explained. Justice Policy Institute. Retrieved online from: http://www.justicepolicy.org/news/8775 
Nishioka, V. (2012). What we know about reducing disproportionate suspension rates for students of color: A literature summary. Regional Educational Laboratory at Education Northwest. Retrieved online at: https://www.cosa.k12.or.us/downloads/profdev/Safe\%20Schools\%20Summit/SOC.pdf

Noddings, N. (1984). Caring: A feminine approach to ethics and moral education. Berkley: University of California Press.

Noguera, P. A. (2003). School, prisons and social implications of punishment: Rethinking disciplinary practices. Theory into Practice, 42(4), 341-351.

Noltemeyer, A. L., \& Mcloughlin, C. S. (2010). Changes in exclusionary discipline rates and disciplinary disproportionality over time. International Journal of Special Education, 25(1), 12.

Olson, B., \& Viola, J. (2007, September). Chicago public schools high school peer jury program evaluation report. DePaul University.

Owens, J., Wettach, J., \& Hoffman, K. C. (2015). Instead of suspension: Alternative strategies for effective school discipline. Duke University Law School and Center for Child and Family Policy. Retrieved online from: https://law.duke.edu/childedlaw/schooldiscipline/downloads/instead_of_suspension.pdf Payne, A. A., \& Welch, K. (2010). Modeling the effects of racial threat on punitive and restorative school discipline practices. Criminology, 48, 1019-1062.

PEW Center on the States. (2008). One in 100: Behind bars in America. Washington, DC.

Philips, E. N., Berg, M. J., Rodriguez, C., \& Morgan, D. (2010). A case study of participatory action research in a public New England middle school: Empowerment, constraints and challenges. American Journal of Community Psychology, 46, 179-194. 
Pipho, C. (1999, June). Living with zero tolerance. Phi Delta Kappan, 79(10), 725-727.

Planty, M., Kena, G., \& Hannes, G. (2009). The condition of education in 2009 in brief (NCES 2009-082). National Center for Educational Statistics, Institute of Educational Sciences, U.S. Department of Education, Washington, DC.

Pranis, K., Stuart, B., \& Wedge, M. (2003). Peacemaking circles: From crime to community. St. Paul, MN: Living Justice Press.

Puzzanchera, C., \& Adams, B. (2011). Juvenile arrests 2009. Office of Juvenile Justice and Delinquency Prevention. Retrieved on July 25, 2016 from http://www.ojjdp.gov/pubs/236477.pdf

Raffaele-Mendez, L. M., \& Knoff, H. M. (2003). Who gets suspended from school and why: A demographic analysis of schools and disciplinary infractions in a large school district. Education and Treatment of Children, 26, 30-51.

Rausch, M. K., \& Skiba, R. J. (2005, April). The academic cost of discipline: The relationship between suspension/expulsion and school achievement. Paper presented at the annual meeting of the American Educational Research Association, Montreal, Canada.

Resitenberg, N. (2006, October 18-20). Applying the framework: Positive youth development and restorative practices. The Next Step: Developing Restorative Communities. IIRP $8^{\text {th }}$ International Conference, Bethlehem, PA.

Rimer, S. (2004, January 4). 'Unruly students facing arrest, not detention'. New York Times, p. A1.

Roujanavong, W. (2005, November). Restorative justice: Family and community group conferencing (FCGC) in Thailand. Paper presented at the Seventh International Conference on Conferencing, Circles and other Restorative Practices, Manchester, UK. 
Roulston, K. (2010). Considering quality in qualitative interviewing. Qualitative Research, 10(2), 199-228.

Sagor, R. (1992). How to conduct collaborative action research. Alexandria, VA: Association for Supervision and Curriculum Development.

Samuels, E. F. (2001). The peer mediation process in secondary schools. Doctoral thesis. Ontario Institute for Studies in Education, University of Toronto.

Schenk, B. (2007, November). The restorative practice framework in school communities: Translating the Australia experience into the Canadian context. Paper presented at the $10^{\text {th }}$ International Institute for Restorative Practices World Conference.

Schiff, M. (2013). Dignity, disparity, and desistance: effective restorative justice strategies to plug the school to prison pipeline. Florida Atlantic University.

Simon, J. (2006). Governing through crime: How the war on crime transformed American democracy and created a culture of fear. New York, NY: Oxford University Press.

Skiba, R. J. (2002). Zero tolerance, zero evidence: An analysis of school disciplinary practice. Indiana Education Policy Center. Policy Research Report, August 2000.

Skiba, R. J., Horner R. H., Chung, C.-G., Rausch, M. K., May, S. L. \& Tobin, T. (2011). Race is not neutral: A national investigation of African American and Latino disproportionality in school discipline. School Psychology Review, 40(1), 85-107.

Skiba, R. J., Michael, R. S., Nardo, A. C., \& Peterson, R. L. (2002). The color of discipline: Sources of racial and gender disproportionality in school punishment. Russell: The Journal of the Bertrand Russell Archives, 34(4).

Skiba, R. J., \& Peterson, R. (1999). The dark side of zero tolerance: Can punishment lead to safe schools? Phi Delta Kappan, 80(5), 372-382. 
Skiba, R. J., \& Peterson, R. (2003). Teaching the social curriculum: School discipline as instruction. Preventing School Failure, 47, 66-74.

Skiba, R. J., \& Peterson, R. L. (2000). School discipline at a crossroads: From zero tolerance to early response. Exceptional Children, 66(3), 335-347.

Skiba, R. J., \& Rausch, M. K. (2006). Zero tolerance, suspension and expulsion: Questions of equity and effectiveness. In C. M. Evertson, \& C. S. Weinstein (Eds.), Handbook of classroom management: Research, practice and contemporary issues (pp. 1063-1089). Retrieved from https://www.routledgehandbooks.com/doi/10.4324/9780203874783

Skiba, R. J., Ritter, S., \& Simmons, A. (2005). The safe and responsive schools project: A school reform model for implementing best practices in violence prevention. In $\mathrm{S}$. Jimerson, \& M. Furlong (Eds.), Handbook of school violence and school safety. New York, NY: Routledge.

Soto-Vigil Koon, D. (2013). Exclusionary school discipline: An Issue brief and review of the literature: The Chief Justice Earl Warren Institute of Law and Social Policy. Retrieved from www.law.berkeley.edu/files/BMOC_Exclusionary_School_Discipline_Final.pdf.

Sprick, R. S., Sprick, M., \& Garrison, M. (1992). Foundations: Establishing positive discipline policies. Longmont, CO: Sopris West.

Spring, J. H. (2012). Deculturalization and the struggle for equity: A brief history of the education of dominated cultures in the United States. New York, NY: McGraw Hill.

Stake, R. E. (1995). The art of the case study. Thousand Oaks, CA: Sage Publications.

Stinchcomb, J., Bazemore, G., \& Resitenburg, N. (2006). Beyond zero tolerance. Youth Violence and Juvenile Justice, 4(2), 123-147. 
Summer, M. D., Silvermann, C. J., \& Frampton, M. L. (2010). School based restorative justice as an alternative to zero tolerance policies: Lessons from West Oakland, CA. Berkeley, CA: Thelton E. Henderson Center for Social Justice.

Susman, G. I., \& Evered, R. D. (1978). An assessment of the scientific merits of action research. Administrative Science Quarterly, 23, 582-603.

Theriot, M. (2009). School resource officers and the criminalization of student behavior. Journal of Criminal Justice, 37, 280-287.

Thompson, J. (2016). Eliminating zero tolerance policies in schools: Miami-Dade county public school's approach. Brigham Young University Education and Law Journal, 2.

Townsend, B. (2000). Disproportionate discipline for African American children and youth: Culturally-responsive strategies for reducing school suspensions and expulsions. Exceptional Children, 66, 381-391.

Tubin, D., Mioduser, D., Nachmias, R., \& Forkosh-Baruch, A. (2003). Domain and levels of pedagogical innovation in schools using ICT: An analysis of ten Israeli schools. Education and Information Technologies, 8, 127-145

Umbreit, M. S., Coates, R. B., \& Vos, B. (2002). The impact of restorative justice conferencing: A multinational perspective. British Journal of Community Justice.

United States Department of Education. (2014a). Persistent disparities found throughout comprehensive civil rights survey underscored need for continued focus on equity. Retrieved online from: https://www.ed.gov/news/press-releases/ United States Department of Education. (2014b). Guiding principles: A resource guide for improving school climate and discipline. Retrieved online from: https://www2.ed.gov/policy/gen/guid/school-discipline/guiding-principles.pdf 
Vavrus, F., \& Cole, K. (2002). “I didn't do nothing”: A discursive construction of school suspension. Urban Review, 34, 87-111.

Wachtel, T. (2009, November 5). My three decades of using restorative practices with delinquent and at-risk youth: Theory, practices and research outcome. A paper presented at the First World Congress on Restorative Juvenile Justice, Lima, Peru.

Wachtel, T. (1999, February 16-18). Restorative justice in everyday life: Beyond the formal ritual. Paper presented at the Reshaping Australian Institutions Conference; Restorative Justice in Civil Society, The Australian National University, Canberra.

Wachtel, T. (2013). Dreaming of a new reality: How restorative practices reduce crime and violence, improve relationships, and strengthen civil society. Bethlehem, PA: The Pipers Press.

Wald, J., \& Losen, D. J. (2003). Defining and redirecting a school-to-prison pipeline. In J. Wald, \& D. J. Losen (Eds.), New directions for youth development (pp. 9-15). San Francisco, CA: Jossey-Bass.

Wallace, J. M., Wallace, C. M., \& Bachman, J. G. (2008). Racial, ethnic, and gender differences in school discipline among U. S. high school students: 1991-2005. Abstract Introduction. Educational Review, 59, 1991-2005.

Watts, H. (1985). When teachers are researchers, teaching improves. Journal of Staff Development, 6(2), 118-127.

Weitekamp, E. (1999). The history of restorative justice. In G. Bazemore, \& L. Walgrave (Eds.), Restorative juvenile justice: Repairing the harm of youth crime (pp. 75-102). New York, NY: Criminal Justice Press. 
Wu, S. C., Pink, W. T., Crain, R. L., \& Moles, O. (1982). Student suspension: A critical reappraisal. Urban Review, 14, 245-303.

Zehr, H. (1990). Changing lenses: A new focus for crime and justice. Scottsdale, PA: Herald Press.

Zehr, H. (2002). The little book of restorative justice. Intercourse, PA: Good Books.

Zehr, H. (2005). Changing lenses: A new focus for crime and justice ( $3^{\text {rd }}$ ed.). Scottsdale, PA: Herald Press. 


\section{APPENDIX A: PARTICIPANT BACKGROUND FORM}

The Participant Background form has been developed in order to provide the researcher with a general understanding on the participant's general experiences in education.

Research Study Participant Background Form

Name: Today's Date:

Ethnicity origin (or Race): Please specify your ethnicity.

$\square$ White $\square$ Hispanic or Latino $\quad \square$ Black or African American

$\square$ Asian/Pacific Islander $\quad \square$ Native American or American Indian $\quad \square$ Other

Current Position at Barrington High School:

$\square$ Guidance Counselor $\quad \square$ Social Worke

$\square$ Student Intern $\quad \square$ Dean $\square$ Other:

Years of experience in current position at Barrington High School:
$\square 1-4$ years
$\square 5-10$ years
$\square 11-20$ years
$\square 20+$ years

Total years of experience in education:
$\square 1-4$ years
$\square 5-10$ years
$\square 11-20$ years
$\square 20+$ years

Highest educational degree held:

$\square$ Bachelor's

$\square$ Master's

$\square$ Professional

$\square$ Doctoral 


\section{APPENDIX B: PARTICIPANT SURVEY}

The Research Survey uses a 5-point Likert scale and is designed to rate participant knowledge, perceptions and attitude about current school discipline practices and the restorative justice model.

Participant Research Survey (Pre/Post)

The following pages contain a number of statements with which some people agree and others disagree. Please rate how much you personally agree or disagree with these statements - how much they reflect how you think or feel personally. Use the following scale:

(1) totally disagree

(2) generally disagree

(3) neither agree nor disagree

(4) generally agree

(5) totally agree

Please answer the following questions, using the scale above, as they relate to your knowledge, feelings and/or experiences as a staff member at Barrington High School.

\begin{tabular}{|c|c|}
\hline Current discipline procedures are an effective means for addressing misbehavior. & 12345 \\
\hline I am aware of the consequence range assigned to students for variety of discipline events. & 12345 \\
\hline The school discipline procedures we have in place treat all students fairly. & 123445 \\
\hline $\begin{array}{l}\text { In this school, we teach students ways to resolve disagreements so that everyone can be } \\
\text { satisfied with the outcome. }\end{array}$ & 12345 \\
\hline Students in this school are generally well behaved. & 12345 \\
\hline I am aware of what behaviors result in a discipline referral. & 12345 \\
\hline Students should not be offered extrinsic rewards as motivation to improve their behavior. & $\begin{array}{lllll}1 & 2 & 3 & 4 & 5\end{array}$ \\
\hline This school relies heavily on adult-imposed consequences in response to challenging behavior. & 12345 \\
\hline $\begin{array}{l}\text { Teachers frequently write referrals to address behavior issues that take place inside the } \\
\text { classroom. }\end{array}$ & 12345 \\
\hline $\begin{array}{l}\text { Classroom teachers are satisfied with the behavioral consequences a student receives after a } \\
\text { referral. }\end{array}$ & $123 \quad 345$ \\
\hline There is a support system in place to assist offenders in changing their behavior. & 12345 \\
\hline The school is consistent with the enforcement of rules for student wrongdoing. & 12345 \\
\hline Parents are actively involved in school discipline practices. & 12345 \\
\hline $\begin{array}{l}\text { Our response to discipline issues is primarily emergent and reactive, rather than planned and } \\
\text { proactive. }\end{array}$ & 12345 \\
\hline Students should not be suspended from school. & 12345 \\
\hline Teachers should be more involved in the enforcement of student behavior practices. & 12345 \\
\hline Most of our school discipline issues come from our minority students. & 12345 \\
\hline $\begin{array}{l}\text { Our school needs to provide more social/emotional support to students involved with } \\
\text { classroom discipline. }\end{array}$ & 12345 \\
\hline $\begin{array}{l}\text { I am aware of the policies and procedures for student discipline as outlined in the school } \\
\text { handbook. }\end{array}$ & 12345 \\
\hline
\end{tabular}




\begin{tabular}{|c|c|c|c|c|}
\hline Teachers feel supported by school administration with consideration to student behavior & 12 & 3 & 4 & 5 \\
\hline $\begin{array}{l}\text { Classroom teachers most often address student behavior issues on their own, without writing a } \\
\text { referral. }\end{array}$ & 12 & 3 & 4 & 5 \\
\hline Our school needs a more strictly enforced set of rules and immediate consequences. & 12 & 3 & 4 & 5 \\
\hline Out of school suspensions are effective consequences to changing student behavior. & 12 & 3 & 4 & 5 \\
\hline $\begin{array}{l}\text { There are many "Frequent flyers" whose behavior does not improve despite frequent exposure } \\
\text { to the discipline program. }\end{array}$ & 12 & 3 & 4 & 5 \\
\hline Our school has a lot of resources designed to prevent student behavior problems. & 12 & 3 & 4 & 5 \\
\hline Offenders are encouraged to accept responsibility for their actions. & 12 & 3 & 4 & 5 \\
\hline Finding alternatives to out-of-school suspension will make the discipline office look "weak." & 12 & 3 & 4 & 5 \\
\hline I am involved in assigning discipline consequences. & 12 & 3 & 4 & 5 \\
\hline The school should do more to support students with their behavioral issues. & 12 & 3 & 4 & 5 \\
\hline Discipline referrals should all be treated the same, regardless of the student involved. & 12 & 3 & 4 & 5 \\
\hline I feel safe in the school. & 12 & 3 & 4 & 5 \\
\hline Students know what to do if they are bullied, or if they see the bullying/harassment of another. & 12 & 3 & 4 & 5 \\
\hline $\begin{array}{l}\text { In-school suspension is an opportunity to provide a supportive environment for students to } \\
\text { resolve conflict. }\end{array}$ & 12 & 3 & 4 & 5 \\
\hline $\begin{array}{l}\text { Students that have been suspended, often return with better self-control and decision-making } \\
\text { skills. }\end{array}$ & 12 & 3 & 4 & 5 \\
\hline $\begin{array}{l}\text { Other students and staff that are negatively impacted by wrongdoing are given a voice, directly } \\
\text { or indirectly. }\end{array}$ & 12 & 3 & 4 & 5 \\
\hline $\begin{array}{l}\text { There is good communication between staff and administration after a referral has been } \\
\text { addressed. }\end{array}$ & 12 & 3 & 4 & 5 \\
\hline $\begin{array}{l}\text { Change to current school discipline practices is a topic many staff are interested in learning } \\
\text { more about. }\end{array}$ & 12 & 3 & 4 & 5 \\
\hline Students will benefit by providing alternative discipline opportunities. & 12 & 3 & 4 & 5 \\
\hline Offenders are given an opportunity to repair the harm caused by their actions. & 12 & 3 & 4 & 5 \\
\hline The primary goal of student discipline referrals is to change future behavior. & 12 & 3 & 4 & 5 \\
\hline
\end{tabular}


Adapted from Howard Zehr (1990).

\section{OUR RESTORATIVE SHIFT}

BLAME-FIXING $\rightarrow$

PAST BEHAVIOR $\rightarrow$

PUNISHMENT $\rightarrow$

NEGLECT VICTIM NEEDS $\rightarrow$

NEGLECT OFFENDER VOICE $\rightarrow \quad$ OFFENDER VOICE

NEGLECT RELATIONSHIPS $\rightarrow$ REBUILD RELATIONS
PROBLEM SOLVING

FUTURE BEHAVIOR

REPAIR

VICTIM NEEDS 